University of Rhode Island

DigitalCommons@URI

Open Access Master's Theses

2012

\title{
IMPACT OF THE HEALTH IT UP INTERVENTION ON PLASMA LIPIDS AND GLUCOSE IN COLLEGE STUDENTS
}

Shira Hirshberg

University of Rhode Island, shira.hirshberg@gmail.com

Follow this and additional works at: https://digitalcommons.uri.edu/theses

\section{Recommended Citation}

Hirshberg, Shira, "IMPACT OF THE HEALTH IT UP INTERVENTION ON PLASMA LIPIDS AND GLUCOSE IN COLLEGE STUDENTS" (2012). Open Access Master's Theses. Paper 102.

https://digitalcommons.uri.edu/theses/102

This Thesis is brought to you for free and open access by DigitalCommons@URI. It has been accepted for inclusion in Open Access Master's Theses by an authorized administrator of DigitalCommons@URI. For more information, please contact digitalcommons-group@uri.edu. 
IMPACT OF THE HEALTH IT UP INTERVENTION ON PLASMA LIPIDS AND GLUCOSE IN COLLEGE STUDENTS

BY

SHIRA HIRSHBERG

\section{A THESIS SUBMITTED IN PARTIAL FULFILLMENT OF THE REQUIREMENTS FOR THE DEGREE OF \\ MASTER OF SCIENCE}

IN

NUTRITION

UNIVERSITY OF RHODE ISLAND

2012 


\title{
MASTER OF NUTRTION THESIS \\ OF \\ SHIRA HIRSHBERG
}

\section{APPROVED:}

Thesis Committee:

\author{
Major Professor: Ingrid Lofgren \\ Kathleen Melanson \\ Disa Hatfield \\ Nasser H. Zawia \\ DEAN OF THE GRADUATE SCHOOL
}




\section{ABSTRACT}

Purpose: Cardiovascular diseases (CVD) cause over 2200 American deaths daily and include coronary heart disease (CHD), the fifth leading cause of death in young adults. Those with diabetes mellitus are especially vulnerable to $\mathrm{CHD}$, as heart disease death rates are two to four times higher in this population. Blood lipids and glucose can be used to estimate CVD risk, and include elevated plasma total cholesterol (TC), low-density lipoprotein cholesterol (LDL-C), triacylglycerol (TAG), low high-density lipoprotein cholesterol (HDL-C), physical inactivity, overweight and obesity, diabetes mellitus and impaired fasting plasma glucose. Prevalence of these risk factors is evident in college students across the country. Lifestyle interventions to reduce the development of type 2 diabetes and CVD are feasible and costeffective, and include improving nutrition and increasing physical activity.

Design: Using a quasi-experimental design, the Health It Up Intervention included five 20-minute lessons embedded into a general nutrition course. Data were collected at the beginning and end of the semester to examine the effect of the intervention on diet, body composition and markers of chronic disease risk.

Setting: The intervention was conducted at a mid-sized northeastern university during the spring semester in 2010. 
Subjects: Eighty-three students between the ages of 18 and 24 years, taking a general nutrition course, participated in the intervention. One student dropped the course during the intervention and did not finish the study. Intervention: The intervention was interactive and included food sampling, group activities, and presentations utilizing PowerPoint. The focus of the intervention was to teach students how to improve their diet and increase their physical activity to reduce chronic disease risk.

Measures: Biochemical data were collected using a Cholestech LDX analyzer and dietary data were collected using food screeners. Body composition was analyzed using a handheld bioelectrical impedance device and weight was measured on a digital scale.

Results: Mean age was $19.3 \pm 1.4$ years, mean BMI was $23.5 \pm 3.6 \mathrm{~kg} / \mathrm{m}^{2}$, and the sample consisted of $18 \%$ males and $82 \%$ females. A mixed betweenwithin subjects ANOVA assessed the impact of the intervention on body weight and composition, plasma lipids and glucose. The main effect for time was significant for TC, HDL-C and glucose, with a decrease in all three concentrations from baseline to post-intervention. Wilcoxin signed ranks tests were used to measure change in dietary variables, and total intake of fruits and vegetables increased from baseline to post-intervention.

Conclusion: Diet and physical activity education embedded in a college class may be a way to decrease chronic disease risk factors in young adults. 
A strength of the study is that it could be easily replicated and utilized by other universities as the cost of the intervention itself was low. A limitation of the study is the inability to distinguish between the effect of the general nutrition course and the intervention. Future research should incorporate a similar intervention into a non-nutrition course to determine the effect of the intervention alone. 


\section{ACKNOWLEDGEMENTS}

First of all, I'd like to thank Ingrid Lofgren for her mentorship, guidance, support, and care throughout my three years at URI. For working tirelessly to make the study and the writing happen l'd like to thank Jill Fernandes, Nowen Beebe, Katy Hartman, Katherine Gill, Noereem Mena, Chungyee Pho, Erica Burdon, Jamie Kievit, Jen Arts, Steven Magnanti, Emily Cook, Kate Cottel, Chelsea Smith, Carly Demos, Elizabeth Valente, and Stephanie Perruzza for study, research, and writing assistance. l'd like to thank Debbe Fate, Laurence Hirshberg, David Hirshberg, Dave Stuebe, Jessi Lipschitz, Meredith Haas, Megan Radka and Tricia Lourenco for their tireless love, support and editing. l'd like to thank Valerie Digidio for her assistance with a million different departmental tasks and finally to thank my thesis committee for their efforts in improving this document. Funding for this project was provided by the United States Department of Agriculture. 


\section{PREFACE}

This thesis was written to comply with the University of Rhode Island Graduate School Manuscript Thesis Format. This thesis contains one manuscript entitled "Health It Up: A Nutrition Education Intervention and its Impact on Chronic Disease Risk in College Students". This manuscript has been written in a form suitable for publication in The American Journal of Health Promotion. 


\section{TABLE OF CONTENTS}

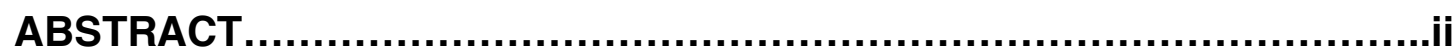

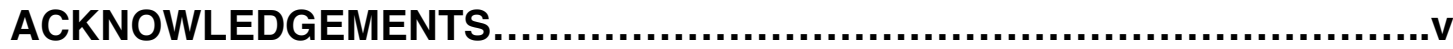

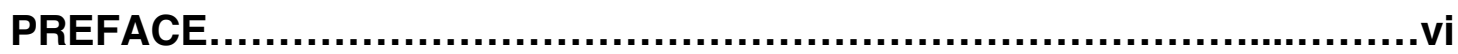

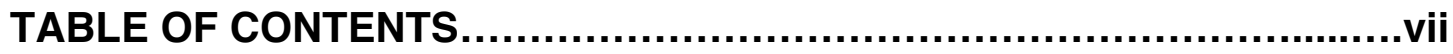

LIST OF TABLES.................................................................iii

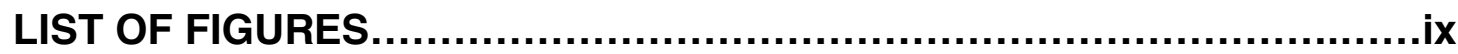

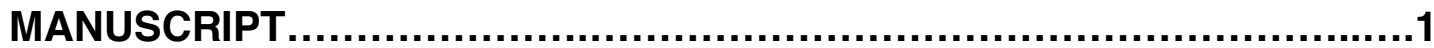

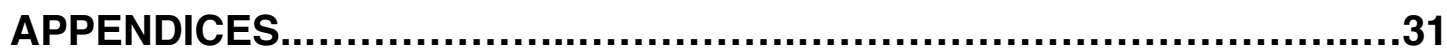

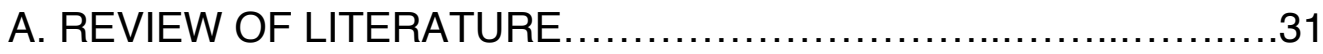

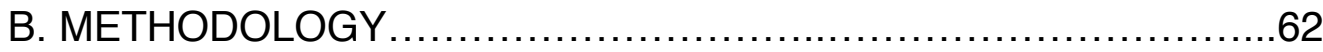

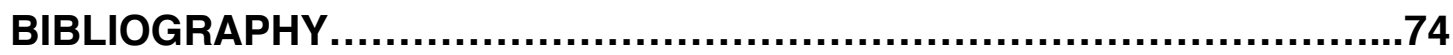




\section{LIST OF TABLES}

TABLE

PAGE

Table 1. Health It Up Intervention Topics and Activities........................11

Table 2. Health It Up Intervention Participant Descriptive Characteristics......14

Table 3. Prevalence of Chronic Disease Risk Factors in Health It Up

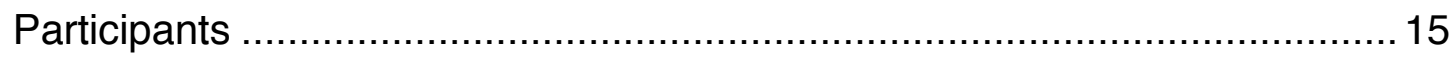

Table 4. Effect of Time on Anthropometric, Clinical, and Biochemical Variables

in Health It Up Intervention Participants.....................................16

Table 5. Fruit and Vegetable Intake of Health It Up Intervention

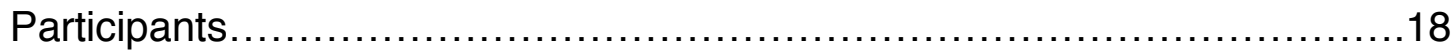

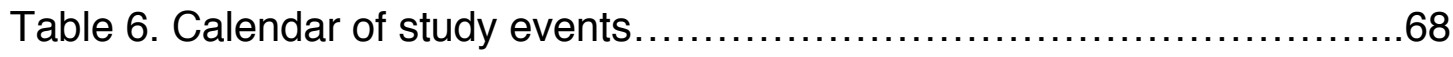




\section{LIST OF FIGURES}

\section{FIGURE}

PAGE

Figure 1. Change in Total Cholesterol by Days of Attendance in

Health It Up Intervention Participants.

Figure 2. Change in Glucose by Days of Attendance in

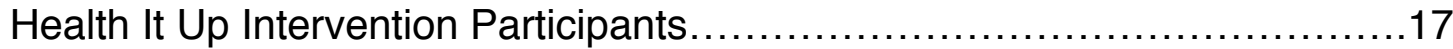

Figure 3. Atherosclerosis Formation............................................ 41

Figure 4. Mechanism of action for the down-regulation of CETP.............47

Figure 5. Production of superoxide by the mitochondrial electron-transport

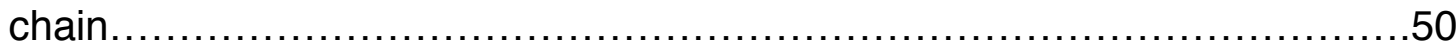




\section{MANUSCRIPT INTRODUCTION PAGE MANUSCRIPT - I}

To be submitted to The American Journal of Health Promotion

\section{Health It Up: A Nutrition Education Intervention and its Impact on Chronic Disease Risk in College Students}

Shira Hirshberg, Ingrid Lofgren

Corresponding Author: Ingrid Lofgren, PhD, RD, LDN

Department of Nutrition and Food Sciences

The University of Rhode Island

10 Ranger Rd, 301 Ranger Hall

Kingston, RI 02881

Phone: 401.874 .5706

Email: ingridlofgren@uri.edu 


\section{HEALTH IT UP: A NUTRITION EDUCATION INTERVENTION AND ITS IMPACT ON CHRONIC DISEASE RISK IN COLLEGE STUDENTS}

\section{ABSTRACT}

Purpose: Determine whether a nutrition and physical activity intervention embedded into a general nutrition course can impact risk factors for cardiovascular disease and type 2 diabetes mellitus.

Design: Quasi-experimental design with baseline and post-intervention testing.

Setting: Mid-sized northeastern university.

Subjects: Eighty-three students, 18-24 years old. One student didn't complete the intervention.

Intervention: The intervention included food sampling, group activities, partner discussions and presentations.

Measures: Biochemical data were collected using a Cholestech LDX analyzer, anthropometric data collected using standard procedures, and food data were collected using screeners.

Results: Mean age was $19.3 \pm 1.4$ years, mean BMI was $23.5 \pm 3.6 \mathrm{~kg} / \mathrm{m}^{2}$, and the sample was $82 \%$ female. A mixed between-within subjects ANOVA assessed the impact of the intervention on body weight and composition, plasma lipids and glucose. The main effect for time was significant for TC, 
HDL-C and glucose, with a decrease in all three concentrations from baseline to post-intervention.

Conclusion: This intervention could be easily replicated and utilized by other universities at low cost. The inability to distinguish between the effect of the general nutrition course and the intervention is a limitation of the study. Future research should incorporate a similar intervention into a non-nutrition course to determine the effect of the intervention alone. This intervention may decrease chronic disease risk factors in young adults. 


\section{PURPOSE}

Cardiovascular diseases (CVD) cause over 2200 American deaths daily ${ }^{1}$ and include stroke, high blood pressure, heart failure, and coronary heart disease $(\mathrm{CHD})$. Coronary heart disease is the number one cause of death in the US, and the fifth leading cause of death in young adults. ${ }^{2}$ Those with diabetes mellitus are especially vulnerable to $\mathrm{CHD}$, as heart disease death rates are two to four times higher in this population. ${ }^{3}$ This increased morbidity and mortality is largely caused by hyperglycemia, a key risk factor for CVD. ${ }^{4}$ The prevalence of total diabetes is increasing rapidly, ${ }^{1}$ due, in part to a doubling specifically in the incidence of type 2 diabetes mellitus (T2D) in certain populations over the past 30 years. ${ }^{5}$ Lifestyle interventions to reduce the development of $\mathrm{T}^{2} \mathrm{D}^{3}$ and $C V \mathrm{D}^{6}$ are feasible and cost-effective, and include improving dietary intake and increasing physical activity. ${ }^{7}$

College students are not meeting diet or physical activity recommendations, and so are an important population for chronic disease prevention. ${ }^{8}$ Dyslipidemia in college students tends to track into adulthood ${ }^{9}$ and predicts future risk of CVD and diabetes. ${ }^{7}$ The transition from adolescence to adulthood comes with a shift in responsibility for food choices. ${ }^{10}$ Most college students leave the controlled food environment of their childhood homes for buffet-style dining halls ${ }^{11}$ with unlimited food availability. This new responsibility for food choices combined with the heavy caloric load of binge drinking (up to $44 \%$ of college students), ${ }^{12}$ creates an environment where 
students gain weight about six times faster than the general population, ${ }^{13}$ resulting in an overweight and obesity rate of $35 \%{ }^{8}$

Students who gain weight in college tend to stay overweight ${ }^{14}$ and this weight gain can result in dyslipidemia, ${ }^{15}$ including elevated plasma total cholesterol (TC), and in hyperglycemia, or elevated plasma glucose. ${ }^{16}$ This explains why weight status, as measured by body mass index (BMI), in young adults is positively associated with $\mathrm{CHD}$ risk $^{17}$ and negatively correlated with self-reported health related quality of life 20 years later. ${ }^{18}$ College students across the country show prevalence of chronic disease risk factors, including elevated TC ranging from $11.7^{19}-27 \%^{20}$ and elevated glucose from $5.3^{21}-7 \%^{20}$ of students. This prevalence is concerning, as elevated TC concentrations $\left(\geq 200 \mathrm{mg} / \mathrm{dL}\right.$ ) can double absolute lifetime CHD risk, ${ }^{22}$ and those with impaired fasting glucose (100-110 mg/dL) are four times as likely to develop T2D compared to a normoglycemic person (OR 4.4, 1.3-14.6). ${ }^{23}$

Dietary strategies that can prevent chronic diseases like CHD and T2D include consuming a diet high in fruits, vegetables, nuts, and whole grains, increasing intake of foods with omega three fatty acids and replacing saturated fats with mono- and polyunsaturated fats. ${ }^{24}$ Other strategies include consuming high amounts of dietary fiber ${ }^{25}$ and low amounts of added sugars. ${ }^{26}$ Physical activity is another important element of chronic disease prevention, as there is a dose-response relationship between physical activity and a lowered risk of CVD. ${ }^{27}$ 
Although there is limited research on the impact of combined nutrition and physical activity interventions on CHD risk factors in college students,

research shows that these risk factors can be improved by changing diet $^{6,28}$ and increasing physical activity ${ }^{29}$ in other populations. Dietary education interventions can impact dyslipidemia; hypercholesterolemic adults in the nutrition education intervention group of the Food for Heart program decreased TC by $15.47 \pm 25.1 \mathrm{mg} / \mathrm{dL}$ in four months $(p=0.001) .{ }^{30}$ The purpose of the study was to determine whether five 20-minute intervention classes integrated into an undergraduate general nutrition course could decrease chronic disease risk in college students.

\section{METHODS}

\section{Design}

This study was quasi-experimental, with a prospective pre-post design. The intervention was integrated into a general nutrition course at the URI Kingston campus, taught by a professor in the Department of Nutrition and Food Sciences. Subjects were recruited through in-class and online announcements and were given course extra credit for participation.

Students completed online surveys via SurveyMonkey ${ }^{\circledR}$ and attended a baseline assessment appointment where they received health information including percent body fat, TC, high-density lipoprotein cholesterol (HDL-C), 
low-density lipoprotein cholesterol (LDL-C), triacylglycerol (TAG), glucose, and blood pressure. During five general nutrition classes, 20 minutes were devoted to the Health It Up Intervention, taught by the study coordinator $(\mathrm{SH})$. After the intervention, students completed a post-intervention online survey and came in for another assessment visit where they repeated the same measurements and received the same health information done at baseline. All participants signed the informed consent which had been approved by the URI Institutional Review Board approved all study procedures (IRB \# HU0910-051).

\section{Sample}

Out of 181 students in the class, 91 chose to participate in the Health It Up Intervention. Seven participants were excluded from analysis; five were not between the ages of $18-24$, one dropped the course and one had surgery during the intervention.

\section{Measures}

Students filled out online screeners including: basic demographic information, body weight and dietary history, National Institutes of Health Eating at America's Tables Study All Day Fruit and Vegetable Screener, ${ }^{31}$ (which measures previous month of intake). During baseline testing only, participants also filled out a 4-item health history questionnaire and wrote down three beliefs related to food, eating behaviors or nutrition, which were 
addressed in the intervention classes in order to personalize the nutrition education.

Height was measured with a Seca 220 stadiometer (Seca Corporation, Hamburg, Germany) without shoes, weight was measured in light clothing without shoes, using a calibrated Seca digital 769 scale (Seca Corporation, Hamburg, Germany). Waist circumference was measured at the top of the iliac crest upon exhalation using a Gulick fiberglass, non-stretchable tape measure with an attached tensometer (Patterson Medical, Mount Joy, PA) ${ }^{32}$ Two measurements were taken, and if not within $0.2 \mathrm{~kg}$ of weight, $0.2 \mathrm{~cm}$ of height or $2 \mathrm{~mm}$ of waist circumference, measurements were retaken until two measurements within these parameters were obtained; the mean of the two values was used for analysis. Body mass index was calculated (weight in kilograms/height in meters ${ }^{2}$ ). Percent body fat was determined using a bioelectrical impedance device (Omron HBF-306 Body Fat Analyzer, Omron Health Care Products, Issaquah, WA). The Omron HBF-306 is a validated instrument shown to give similar results as dual-energy $x$-ray absorptiometry. ${ }^{33}$

Finger stick blood tests were performed after a 12-hour fast using a Cholestech LDX table-top analyzer (Cholestech, Hayward, CA). Cholestech LDX is a valid and reliable tool for obtaining TC, HDL-C, nonHDL-C, TAG, calculated LDL-C, TC:HDL-C ratio, and glucose concentrations ${ }^{34}$ and has been used to screen college students for CHD risk. ${ }^{20,35}$ 
Blood pressure was taken with an automatic blood pressure monitor with arm cuff (Omron HEM-711, Omron Health Care Products, Issaquah, WA) after participants were seated for five minutes. One minute after the first measurement, another measure was taken, and if measurements were not within $2 \mathrm{mmHg}$, measurements were retaken one minute apart until two consistent measurements within these parameters were obtained. The mean of the two readings were used for analysis.

The Queen's College Step Test, a validated measure of cardiovascular fitness, was performed according to standard protocols. ${ }^{36,37}$ Briefly, participants stepped up and down on a standard height step (Pro Survivor 601X timer, Accusplit, San Jose, CA) for three minutes in time to a digital metronome (Model DM50, Seiko 5-Yard Co, Ltd.), with males and females stepping at 24 and 22 beats per minute, respectively (metronome set to 96 and 88). Study personnel encouraged participants to keep up a steady rhythm. After completing the test, participant pulse was measured on the left wrist for 15 seconds and recorded. After completing the test, the information from the step test was used to calculate estimated maximal oxygen consumption $\left(\mathrm{VO}_{2 \max }\right)$ using the following equations, which were validated in college students ${ }^{38,39}$ : Women: $\mathrm{VO}_{2 \max }=65.1-(0.1847 \mathrm{XHR})$; Men: $\mathrm{VO}_{2 \max }=88.38-$ $\left(0.157^{*} \mathrm{HR}\right)-\left(0.250^{*}\right.$ weight in $\left.\mathrm{kg}\right)$. 


\section{Intervention}

The Health It Up Intervention aimed to improve CVD risk factors through dietary education, specifically targeting TAG and HDL-C, as these two risk factors were shown to be most prevalent in first-year URI students. ${ }^{21}$ The intervention lessons were comprised of diet and physical activity education, including experiential activities, partner discussion, and food sampling. The intervention was based on research showing the health impact of specific foods (like nuts and fish) and nutrients (like fiber). ${ }^{40}$

Intervention lessons described how diet and physical activity could impact future risk of heart disease and other health issues like cancer risk, body weight, and depression. These lessons included PowerPoint presentations, activities, food sampling and group discussion (Table 1), and handouts were distributed in each lesson (Table 2). Each handout summarized the day's topics and showed where recommended foods could be found on campus. Interactive activities and discussions were completed in small groups of students. Study personnel researched the food beliefs provided by students during baseline testing. Topics based on these beliefs included whether it was unhealthy to eat late at night, and whether breakfast is actually the most important meal of the day. 
Table 1

Health It Up Intervention Topics and Activities

\begin{tabular}{|c|c|c|c|}
\hline Class & Education Goals & Partner Discussion & Interactive Activities \\
\hline 1 & $\begin{array}{l}\text { 1. Consume an overall healthy } \\
\text { diet } \\
\text { 2. Eat more whole grains } \\
\text { 3. How to identify a whole grain } \\
\text { product (reading food labels) }\end{array}$ & $\begin{array}{l}\text { Introduce yourself to your } \\
\text { neighbor and discuss your } \\
\text { favorite foods. }\end{array}$ & $\begin{array}{l}\text { Photo cards with grains on them } \\
\text { are handed out and students are } \\
\text { asked to } \\
\text { Stand up if your card has a whole } \\
\text { grain on it. } \\
\text { Stand up if your card has a } \\
\text { refined grain on it. }\end{array}$ \\
\hline 2 & $\begin{array}{l}\text { 1. Eat less sugar by eating } \\
\text { more natural foods and less } \\
\text { processed foods } \\
\text { 2. Choose lower sugar products } \\
\text { 3. Slowly decrease amount of } \\
\text { sugar used in coffee/tea } \\
\text { 4. Consume more fiber }\end{array}$ & $\begin{array}{l}\text { Did you try any new whole } \\
\text { grain products since our } \\
\text { last class? Did you like } \\
\text { them? }\end{array}$ & $\begin{array}{l}\text { Sample lower sugar Greek yogurt } \\
\text { and high fiber cereals. Students } \\
\text { were offered samples of plain } \\
\text { regular yogurt as well. }\end{array}$ \\
\hline 3 & $\begin{array}{l}\text { 1. Eat } 5 \text { oz of heart healthy } \\
\text { nuts/week } \\
\text { 2. Eat two } 4-0 z \text { portions of fatty } \\
\text { fish each week or } 1 \mathrm{~Tb} \text { canola } \\
\text { oil or } 1 / 2 \text { tsp ground flax seed } \\
\text { each week? } \\
\text { 3. Consume more mono- and } \\
\text { polyunsaturated fats } \\
\text { 4. Limit saturated and trans fats } \\
\text { 5. How to find saturated and } \\
\text { trans fats in foods (reading } \\
\text { labels) }\end{array}$ & $\begin{array}{l}\text { Did you try eating more } \\
\text { high fiber foods? } \\
\text { Did you like them? } \\
\text { Did you reduce your sugar } \\
\text { intake? } \\
\text { Are you used to it? } \\
\text { If not, brainstorm ways to } \\
\text { do it this week. }\end{array}$ & $\begin{array}{l}\text { Discuss the amounts of fat in the } \\
\text { food on your card with your } \\
\text { neighbor. } \\
\text { Sample nuts- pistachios, walnuts, } \\
\text { almonds, pecans, macadamias, } \\
\text { hazelnuts. } \\
\text { Pass around almond food models. } \\
\text { Play the pass the fish food model } \\
\text { game. }\end{array}$ \\
\hline 4 & $\begin{array}{l}\text { 1. Eat more fruits and } \\
\text { vegetables } \\
\text { 2. Follow USDA } \\
\text { recommendations for males and } \\
\text { females (mypyramid.gov) } \\
\text { 3. Make half your plate veggies }\end{array}$ & $\begin{array}{l}\text { Do you like the hummus? } \\
\text { What about the crackers? } \\
\text { Did you try eating more } \\
\text { nuts and fish since last } \\
\text { week? If not, brainstorm } \\
\text { ways to start this week. }\end{array}$ & $\begin{array}{l}\text { Sample garlic and red pepper } \\
\text { hummus and reduced fat triscuits. } \\
\text { Other options are plain and thirty } \\
\text { spices hummus. } \\
\text { What counts? Food models are } \\
\text { distributed and the class is polled } \\
\text { whether they count as a fruit or } \\
\text { vegetable or not. }\end{array}$ \\
\hline 5 & $\begin{array}{l}\text { 1. Achieve ACSM } \\
\text { recommended amounts of } \\
\text { physical activity } \\
\text { 2. Exercise to prevent chronic } \\
\text { diseases and depression }\end{array}$ & $\begin{array}{l}\text { Which fruits did you like? } \\
\text { Which didn't you like? } \\
\text { Have you tried eating } \\
\text { more fruits and vegetables } \\
\text { since last class? If not, } \\
\text { brainstorm ways to start } \\
\text { doing it this week. }\end{array}$ & $\begin{array}{l}\text { Sample dried figs. currents, } \\
\text { dates, yellow raisins, fresh } \\
\text { pineapple, asian pears, canned } \\
\text { mangoes, mandarin oranges, and } \\
\text { frozen blackberries. }\end{array}$ \\
\hline
\end{tabular}

This class had 181 registered students and during each intervention

class, attendance was measured using ResponseCard Radio Frequency Pads

(Turning Technologies, Youngstown, $\mathrm{OH}$ ). Because of school cancellation due

to weather issues, physical activity was only covered in one class. This class 
took place only days before post-intervention testing began, leaving little time for any beneficial effects from changes in physical activity to be detected.

\section{Analysis}

Sample size was calculated using one-tailed paired samples $t$-test in $G^{*}$ Power 3.1, and the necessary number of participants was calculated to be 75 participants based on an effect size of 0.29 , similar to the results seen by Yamaoka et al ${ }^{41}$ using power of 0.80 and an alpha of 0.05 .

All analyses were performed using SPSS, version 19 (SPSS Inc, Chicago, IL). To ensure normality, skewness and kurtosis were examined, and appropriate statistical modifications were applied to non-normally distributed data. Outliers, defined as greater than three standard deviations above or below the mean, were removed at baseline for weight $(n=2)$, waist circumference $($ WC) $(n=2)$, BMI $(n=1)$, TAG $(n=1)$, TC:HDL ratio $(n=1)$, glucose $(n=1)$ and heart beats per minute (step test) $(n=1)$ and at post-intervention for weight $(n=2)$, WC $(n=3), B M I(n=1)$, TAG $(n=2)$, TC:HDL ratio $(n=2)$ and estimated $\mathrm{VO}_{2} \max (n=2)$ to ensure normality after outliers were removed. The following transformation were applied to achieve normality; all variables from the fruit and vegetable screener were square root transformed, except for total fruits and vegetables, which was normally distributed, and both baseline and post-intervention WC were log transformed. Continuous variables are presented as mean \pm standard deviation; categorical variables presented as 
percentages, and consumption frequency data presented as median and range. Seven students did not have Response Radio Frequency Pads, and so their attendance data were entered as missing.

To examine the potential impact of attendance on the variables of interest from baseline to post-intervention, mixed between within analysis of variances (ANOVAs) were run controlling for baseline values. Attendance groups were used as the between factors variable, with non-attenders defined as those who attended 0 classes, partial attenders as those who attended 1-2 classes, and full attenders as those who attended 3-5 classes. Seven covariates were tested for high correlations with the dependent variables (TC, HDL-C, LDL-C, TAG, and glucose). These covariates were BMI, weight loss, TC, HDL-C, LDL-C, TC, and SBP and none were correlated with the dependent variables at post-intervention, and so no covariates were used in the analysis. Significance for all tests was set at alpha=0.05. Effect sizes using partial eta squared were examined, with a small effect $=0.01$, medium effect $=$ 0.06 , large effect $=0.14{ }^{42}$

\section{RESULTS}

The final analysis includes 84 participants, 68 females and 15 males.

The average age was $19.3 \pm 1.4$, and average BMI was $23.5 \pm 3.6 \mathrm{~kg} / \mathrm{m}^{2}$. Only $8 \%$ of participants were nutrition majors, and $24 \%$ were kinesiology/physical 
education majors, leaving $68 \%$ in other majors. The majority of students lived on campus (64\%) and most students were Caucasian (84.3\%) (Table 2).

Table 2

Health It Up Intervention Participant Descriptive Characteristics

\begin{tabular}{|c|c|c|c|c|c|c|}
\hline & \multicolumn{4}{|c|}{ Baseline } & \multirow[b]{2}{*}{$\mathbf{n}$} & \multirow[b]{2}{*}{$\%$} \\
\hline & $\mathrm{n}$ & mean & SD & & & \\
\hline Weight (kg) & 84 & 64.38 & 11.22 & Gender & & \\
\hline Waist Circumference $(\mathrm{cm})$ & 84 & 77.84 & 7.40 & Male & 15 & 18.1 \\
\hline Body Mass Index $\left(\mathrm{kg} / \mathrm{m}^{2}\right)$ & 84 & 23.40 & 3.60 & Female & 68 & 81.9 \\
\hline Percent Body Fat & 84 & 22.41 & 7.04 & Major & & \\
\hline Total Cholesterol (mg/dL) & 83 & 169.18 & 26.47 & $\begin{array}{l}\text { Nutrition and } \\
\text { Food Science }\end{array}$ & 7 & 8.4 \\
\hline HDL Cholesterol (mg/dL) & 78 & 63.82 & 15.70 & Kinesiology & 20 & 24.1 \\
\hline Triacylglycerol (mg/dL) & 77 & 99.25 & 39.16 & Other & 56 & 67.5 \\
\hline LDL Cholesterol (mg/dL) & 72 & 84.71 & 22.95 & $\begin{array}{l}\text { Living } \\
\text { Arrangements }\end{array}$ & & \\
\hline Non-HDL Cholesterol (mg/dL) & 77 & 103.72 & 24.89 & On-campus & 54 & 65.1 \\
\hline Total Cholesterol:HDL ratio & 74 & 2.69 & 0.65 & Off-campus & 29 & 34.9 \\
\hline Glucose (mg/dL) & 83 & 90.04 & 10.19 & Ethnicity & & \\
\hline Systolic Blood Pressure $(\mathrm{mmHg})$ & 84 & 115.07 & 10.31 & Caucasian & 70 & 84.3 \\
\hline Diastolic Blood Pressure $(\mathrm{mmHg})$ & 84 & 72.69 & 8.32 & $\begin{array}{l}\text { African } \\
\text { American }\end{array}$ & 4 & 4.8 \\
\hline Estimated $\mathrm{VO}_{2 \max }$ & 84 & 38.63 & 5.69 & Other & 9 & 10.8 \\
\hline
\end{tabular}

There is prevalence of CVD risk factors in these university students (Table 3) and the highest prevalence is elevated LDL-C at $18.7 \%$ of students. 
Table 3

Prevalence of Chronic Disease Risk Factors in Health It Up Participants

\begin{tabular}{|lcc|}
\hline Risk Factor & n & Prevalence (\%) \\
\hline Body Mass Index $\geq 25$ & 22 & 26.5 \\
Waist Circumference & 8 & 9.7 \\
Elevated Total Cholesterol & 12 & 14.6 \\
Low HDL Cholesterol & 5 & 6.3 \\
Elevated Triacylglycerol & 12 & 15.4 \\
Elevated LDL Cholesterol & 14 & 18.7 \\
Elevated Glucose & 12 & 14.5 \\
\hline
\end{tabular}

There were significant decreases from baseline to post-intervention in glucose, TC, and HDL-C (Table 4). The study was not powered to detect change between attendance groups, and while the interaction between attendance group and glucose or TC was not significant, partial and fullattenders may have benefitted more from the intervention than non-attenders (Figures 1 and 2). There was no change from baseline to post-intervention in TAG, LDL-C, systolic or diastolic blood pressure, weight, WC, BMI, percent body fat, estimated $\mathrm{VO}_{2 \max .}($ Tables $6-7)$. There was a significant increase in lettuce salad, other vegetables and total fruits and vegetables from baseline to post and a decrease in vegetable soup (Table 5). 
Table 4

Effect of Time on Anthropometric, Clinical, and Biochemical Variables in Health It Up Intervention Participants

\begin{tabular}{|c|c|c|c|c|c|c|c|}
\hline & \multicolumn{3}{|c|}{ Baseline } & \multicolumn{2}{|c|}{ Post } & \multirow[b]{2}{*}{$p$ value } & \multirow[b]{2}{*}{ effect $^{\star}$} \\
\hline & $\mathrm{n}$ & mean & SD & mean & SD & & \\
\hline Weight (kg) & 82 & 64.4 & 11.2 & 64.4 & 11.0 & 0.38 & 0.01 \\
\hline Waist Circumference (cm) & 80 & 77.8 & 7.4 & 77.1 & 1.2 & 0.44 & 0.01 \\
\hline Body Mass Index $\left(\mathrm{kg} / \mathrm{m}^{2}\right)$ & 83 & 23.4 & 3.6 & 23.4 & 3.4 & 0.14 & 0.03 \\
\hline Percent Body Fat & 83 & 22.4 & 7.0 & 22.4 & 7.2 & 0.65 & 0.00 \\
\hline Total Cholesterol (mg/dL) & 83 & 169.2 & 26.5 & 163.2 & 19.0 & 0.04 & 0.06 \\
\hline HDL Cholesterol (mg/dL) & 78 & 63.8 & 15.7 & 57.3 & 12.4 & $<0.001$ & 0.21 \\
\hline Triacylglycerol (mg/dL) & 77 & 99.3 & 39.2 & 93.0 & 36.1 & 0.12 & 0.08 \\
\hline LDL Cholesterol (mg/dL) & 72 & 84.7 & 23.0 & 87.7 & 19.1 & 0.07 & 0.06 \\
\hline Non HDL Cholesterol (mg/dL) & 77 & 103.7 & 24.9 & 105.1 & 20.9 & 0.23 & 0.02 \\
\hline Total Cholesterol:HDL ratio & 74 & 2.7 & 0.7 & 2.9 & 0.6 & $<0.001$ & 0.14 \\
\hline Glucose (mg/dL) & 83 & 90.0 & 10.2 & 83.5 & 7.0 & $<0.001$ & 0.22 \\
\hline $\begin{array}{l}\text { Systolic Blood Pressure } \\
(\mathrm{mmHg})\end{array}$ & 84 & 115.1 & 10.3 & 114.5 & 10.5 & 0.12 & 0.03 \\
\hline $\begin{array}{l}\text { Diastolic Blood Pressure } \\
(\mathrm{mmHg})\end{array}$ & 84 & 72.7 & 8.3 & 71.6 & 7.0 & 0.23 & 0.06 \\
\hline Estimated $\mathrm{VO}_{2 \max } \mathrm{V}$ & 84 & 38.6 & 5.7 & 39.6 & 5.2 & 0.17 & - \\
\hline Fruits and Vegetables (cups) & 83 & 1.8 & 1.1 & 2.2 & 1.3 & .007 & 0.10 \\
\hline
\end{tabular}

this table shows the results from a mixed between within ANOVA and the $p$ value shown is for the main effect for time

${ }^{*}$ Effect size is measured using partial eta squared

LDL: low-density lipoprotein, $\mathrm{HDL}$ : high density lipoprotein, $\mathrm{VO}_{2 \max }$ : Maximum oxygen consumption

$\checkmark$ not normally distributed after log transformation, so was analyzed using Wilcoxin Signed Ranks test, and so no effect size could be determined 
Figure 1

Change in Total Cholesterol by Days of Attendance in Health It Up Intervention Participants*

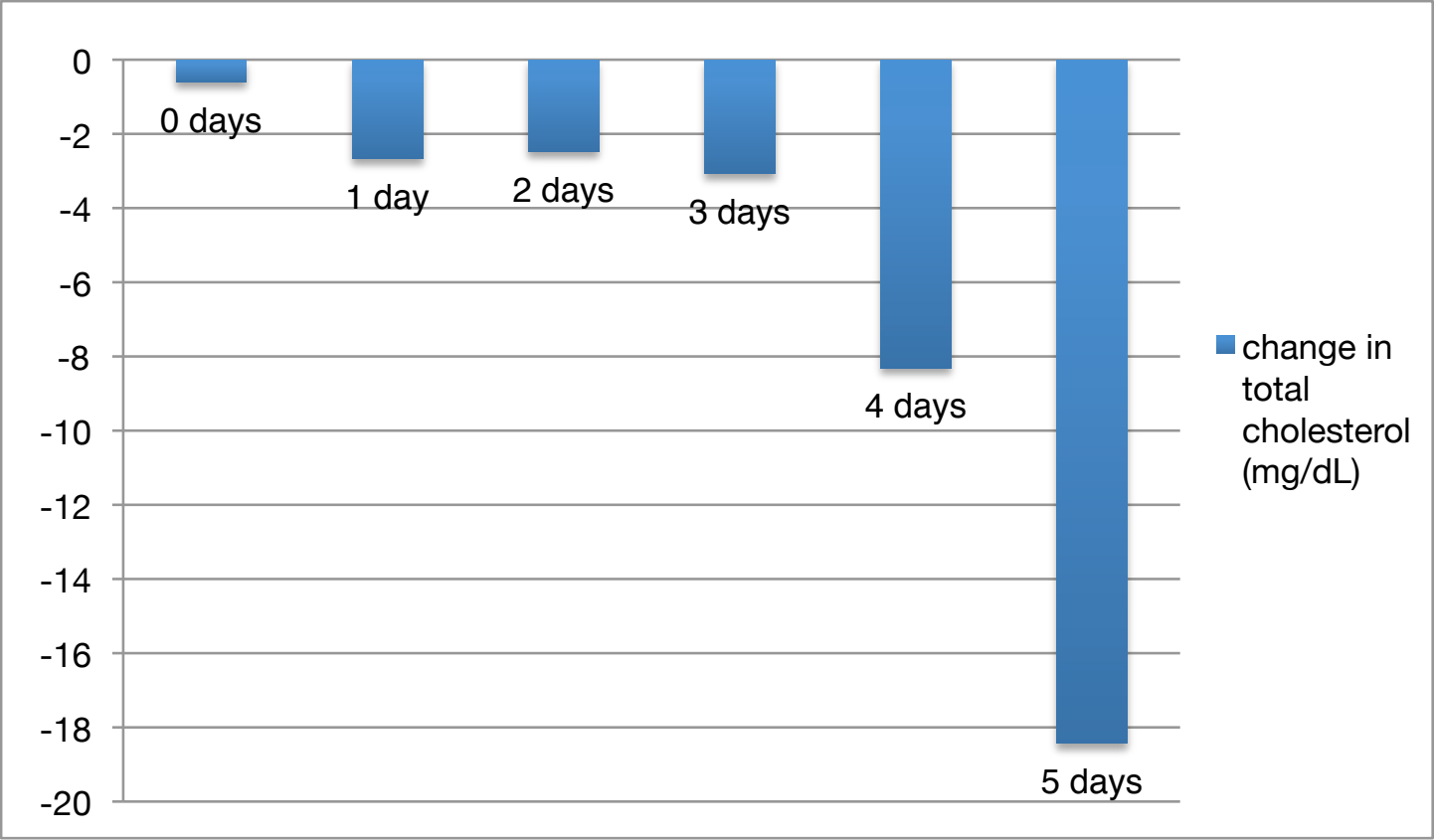

* Attendance data was available for 77 participants

Figure 2

Change in Glucose by Days of Attendance in Health It Up Intervention Participants*

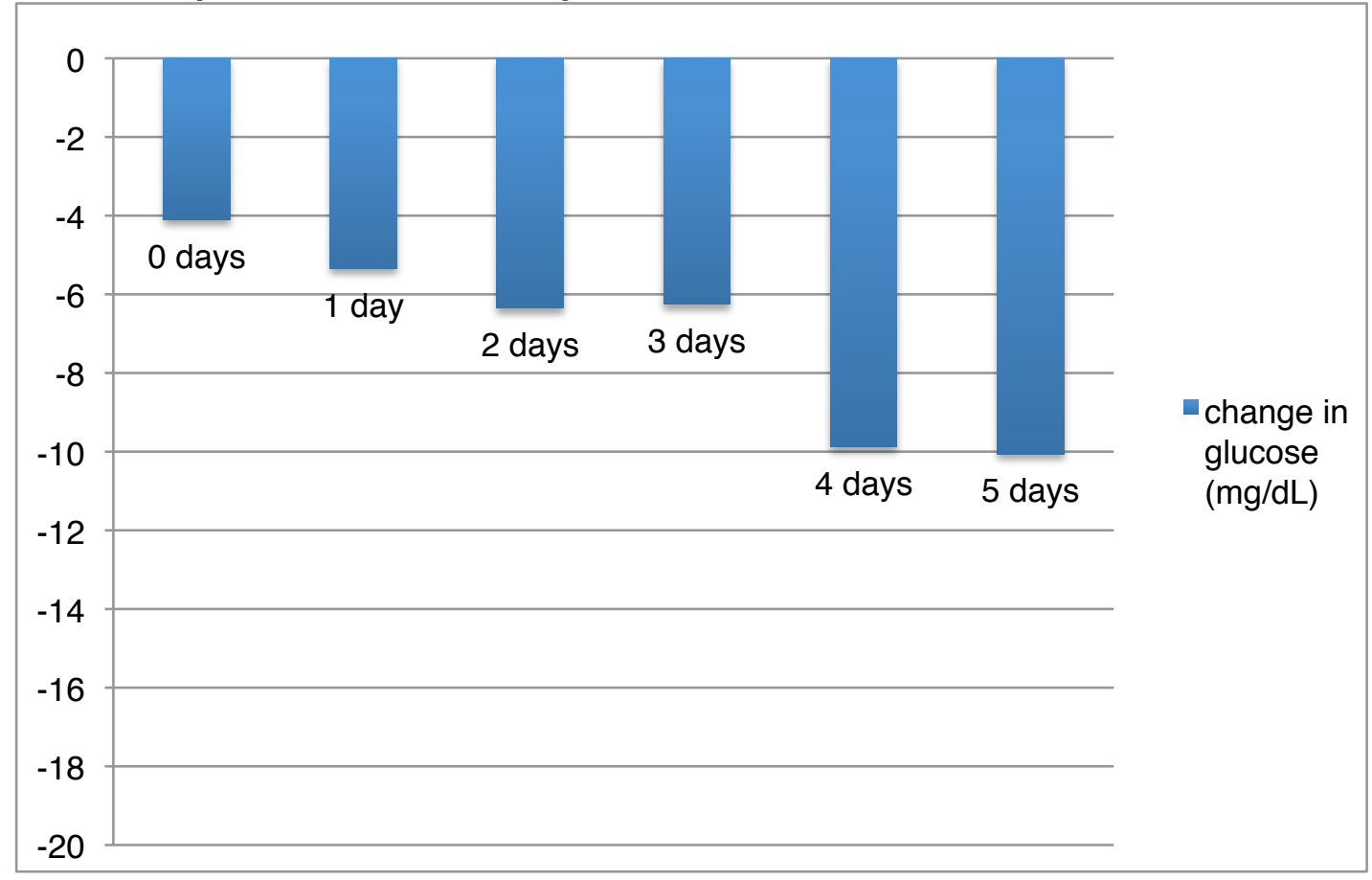

* Attendance data was available for 77 participants 
Table 5

Fruit and Vegetable Intake of Health It Up Intervention Participants^

\begin{tabular}{|l|cc|cc|c|}
\hline \multirow{2}{*}{ Fruit and Vegetables (servings) } & \multicolumn{2}{|c|}{ Baseline } & \multicolumn{2}{c|}{ Post } & \\
& & & & & \\
$100 \%$ Juice & 0.51 & 0.65 & 0.59 & 0.88 & 0.93 \\
Fruit & 0.62 & 0.90 & 0.57 & 0.68 & 0.69 \\
Lettuce Salad & 0.18 & 0.22 & 0.36 & 0.45 & $0.003^{*}$ \\
French Fries or Fried Potatoes & 0.04 & 0.07 & 0.02 & 0.03 & 0.67 \\
Other White Potatoes & 0.05 & 0.06 & 0.08 & 0.10 & 0.09 \\
Beans & 0.01 & 0.03 & 0.03 & 0.06 & 0.08 \\
Other Vegetables & 0.24 & 0.31 & 0.48 & 0.59 & $0.001^{*}$ \\
Tomato Sauce & 0.08 & 0.06 & 0.08 & 0.09 & 0.183 \\
Vegetable Soup & 0.40 & 0.32 & 0.05 & 0.10 & $<0.001^{*}$ \\
Total Fruits and Vegetables & 1.8 & 1.1 & 2.2 & 1.3 & $<0.001^{*}$ \\
\hline
\end{tabular}

$\wedge$ All variables were square root transformed to achieve normality before analyses, except for total fruits and vegetables, which was normally distributed

* significant at $\mathrm{p}<0.05$ Values reflect the average day over the past month of intake

Range of possible scores: 100\% Juice (0-8.3), Fruit (0-3.75), Lettuce Salad (1-4.5), French Fries or Fried Potatoes

(0-6.2), Other white potatoes (0-7), Beans (0-7), Other Vegetables (0-10.1), Tomato Sauce (0-2.6), Vegetable Soup

(0-7.2), Total Fruits and Vegetables (0-56.6)

\section{DISCUSSION}

Cross-sectional research in college students has established the prevalence of CVD risk factors ${ }^{19-21}$ and observational studies have shown that students gain weight from freshman to senior year, ${ }^{43}$ increasing chronic disease risk. ${ }^{44}$ Three previous studies examined the impact of an introductory college nutrition course on self-reported eating behavior ${ }^{45-47}$ but this is the first intervention study to also examine biochemical risk factors for chronic diseases in this population.

The Health It Up Intervention did not result in significant improvements in TAG or HDL-C, the primary risk factors it was designed to impact. Possible 
reasons for this lack of impact include the limited nature of the physical activity component, as aerobic exercise is shown to increase HDL-C. ${ }^{48}$ Another reason may be related to the impact of alcohol on TAG, as binge drinking, common in college students ${ }^{12}$ is associated with increased risk of hypertriglyceridemia. ${ }^{49}$ There was no change in body weight from baseline to post-intervention, and as college students gain an average of about $4 \mathrm{~kg}$ during their first two years of college ${ }^{50}$ weight maintenance is desired.

The intervention did result in significant decreases in two chronic disease risk factors (TC and fasting glucose). Though only about $15 \%$ of students were hyperglycemic at baseline, decreasing glucose even within normoglycemic ranges can decrease risk for diabetes. ${ }^{51} \mathrm{~A}$ similar percentage $(14.6 \%)$ of students had elevated TC at baseline, and the Framingham Heart Study shows that lowering TC decreases risk for CHD; higher concentrations of TC greatly increase lifetime risk of $\mathrm{CHD}$ in all ages of men and women. ${ }^{22}$ While there was also an accompanying significant decrease in HDL-C, this frequently occurs with healthy dietary changes that lead to a decrease in total fat, such as the Dietary Approaches to Stop Hypertension $\operatorname{diet}^{52,53}$ and vegetarian and vegan diets. ${ }^{54}$ The changes in students with low HDL-C at either baseline or post were as follows, $n=4$ participants had normal HDL-C at baseline and low HDL-C at post-intervention testing, $n=3$ participants had low HDL-C at baseline and normal HDL-C at post-intervention testing, and $n=2$ participants had low HDL-C at both baseline and post-intervention testing. 
While CHD mortality has decreased in most populations in the US in the last 30 years, ${ }^{2}$ there are age-specific variations in this trend in both the United States and European countries. ${ }^{55}$ In Portugal and England, longitudinal analysis of rates of CHD mortality showed that mortality decreased in most examined groups, except males aged 35-44 years, which stayed level in Portuga $\left.\right|^{55}$ and increased in England ${ }^{56}$ In the US, death rates from CHD decreased in all age groups except persons aged 25-44, for which they stayed level between 1997 and $2007 .^{2}$ This was attributed to increases in obesity and diabetes and younger men's lack of routine medical treatment and lack of concern for $\mathrm{CHD}$ risk factor management. ${ }^{55}$ Intervening with young people who are just starting to form lifestyle behaviors ${ }^{10}$ should facilitate and promote initiation and maintenance of healthy behaviors. As early changes in diet, physical activity and weight status modify the biological risk factor profile, ${ }^{57}$ there should also be a continued reduction in chronic disease risk throughout the lifecycle. ${ }^{57}$

Nutrition and physical activity are becoming increasingly important issues on the national health agenda, as evidenced by new initiatives like the First Lady's "Let's Move" program. This is because without reversing the trend of increasing numbers of overweight and obese people, poor diet and physical inactivity will soon become the leading preventable cause of mortality. ${ }^{58}$ If interventions aimed to address these concerns are to be accessible, they must be easily implemented using existing personnel and infrastructure at a 
reasonable cost. The Health It Up Intervention fits this model because it utilized an existing college course and was coordinated by one professor and one graduate student with the assistance of undergraduate research assistants.

A strength of the study was the use of food samples to reinforce educational messages, as it is important to establish positive taste preferences for healthful foods in adolescence ${ }^{59}$ Another strength of the study was the provision of health information for students, including measures of their lipid profile, glucose, and percent body fat. A limitation of the study is that it is impossible to separate the effects of the intervention from the effects of the general nutrition class. Taking a general nutrition class has been shown to increase intake of healthful foods, including whole grains ${ }^{60}$ and fruits and vegetables ${ }^{46}$ and so the increase in reported fruits and vegetables in this study could be a attributed to the course and not the intervention. However, the attendance data does suggest that the intervention had some effect.

The American Heart Association's (AHA) 2020 impact goal includes improving cardiovascular health, with optimal levels of seven health behaviors. ${ }^{1}$ Four of these seven are participation in physical activity, healthy dietary intake, total cholesterol $<200 \mathrm{mg} / \mathrm{dL}$, and fasting blood glucose $<100 \mathrm{mg} / \mathrm{dL} .{ }^{1}$ Based on the AHA goals, a nutrition and physical activity intervention similar to Health It Up could help college students improve cardiovascular health. This study is the first to show that a nutrition and 
physical activity intervention integrated into a general nutrition course can modify CVD and T2D risk factors in college students.

\section{SO WHAT?}

College students are not meeting guidelines for diet or physical activity, ${ }^{8}$ which contributes to prevalence of $\mathrm{CHD}$ risk factors. ${ }^{20,61}$ Increasing intake of foods like nuts, ${ }^{62}$ fatty fish, ${ }^{63}$ fruits and vegetables, ${ }^{64,65}$ and whole grains ${ }^{66}$ is associated with a lower risk of chronic disease. Feeding trials using healthful foods like soy and fish can improve risk factors for chronic disease in college students, ${ }^{41}$ but feeding trials are not practical on a population level and so more feasible alternatives must be found to achieve these same dietary changes.

This study builds upon past research that proves the efficacy of nutrition and physical activity education in college students ${ }^{45-47}$ and demonstrates that a targeted intervention embedded into an existing university curriculum can improve disease risk factors in college students. Future research in this area should take place in a class unrelated to nutrition, in order to assess the efficacy of interactive nutrition education intervention alone. 


\section{References}

1. Roger VL, Go AS, Lloyd-Jones DM, et al. Heart disease and stroke statistics--2011 update: a report from the American Heart Association. Circulation. Feb 1 2011;123(4):e18-e209.

2. Health, United States, 2010: With Special Feature on Death and Dying. In: Statistics NCfH, ed. Hyattsville, MD2011.

3. Diabetes Across the United States. (a service of the National Institute of Diabetes and Digestive and Kidney Diseases, National Institutes of Health). Available at: http://www.diabetes.niddk.nih.gov/ populations/index.htm. Accessed Accessed August 24, 2011.

4. Pistrosch F, Natali $\mathrm{A}$, Hanefeld $\mathrm{M}$. Is hyperglycemia a cardiovascular risk factor? Diabetes Care. May 2011;34 Suppl 2:S128-131.

5. Fox CS, Pencina MJ, Meigs JB, Vasan RS, Levitzky YS, D'Agostino $\mathrm{RB}, \mathrm{Sr}$. Trends in the incidence of type 2 diabetes mellitus from the 1970s to the 1990s: the Framingham Heart Study. Circulation. Jun 27 2006;113(25):2914-2918.

6. Retelny VS, Neuendorf A, Roth JL. Nutrition protocols for the prevention of cardiovascular disease. Nutrition in Clinical Practice. Oct-Nov 2008;23(5):468-476.

7. Executive Summary of The Third Report of The National Cholesterol Education Program (NCEP) Expert Panel on Detection, Evaluation, And Treatment of High Blood Cholesterol In Adults (Adult Treatment Panel III). JAMA. May 16 2001;285(19):2486-2497.

8. Huang TT, Harris KJ, Lee RE, Nazir N, Born W, Kaur H. Assessing overweight, obesity, diet, and physical activity in college students. J Am Coll Health. Sep-Oct 2003;52(2):83-86.

9. McMahan CA, Gidding SS, McGill Jr HC. Coronary heart disease risk factors and atherosclerosis in young people. Journal of Clinical Lipidology. 2008;2(3):118-126. 
10. Allan JL, Johnston M, Campbell N. Why do people fail to turn good intentions into action? The role of executive control processes in the translation of healthy eating intentions into action in young Scottish adults. BMC Public Health. 2008;8:123.

11. Gores SE. Addressing nutritional issues in the college-aged client: strategies for the nurse practitioner. J Am Acad Nurse Pract. Jan 2008;20(1):5-10.

12. Wechsler $H$, Lee JE, Kuo M, Seibring M, Nelson TF, Lee H. Trends in college binge drinking during a period of increased prevention efforts. Findings from 4 Harvard School of Public Health College Alcohol Study surveys: 1993-2001. J Am Coll Health. Mar 2002;50(5):203-217.

13. Mihalopoulos NL, Auinger P, Klein JD. The Freshman 15: is it real? $J$ Am Coll Health. Mar-Apr 2008;56(5):531-533.

14. Gordon-Larsen P, Adair LS, Nelson MC, Popkin BM. Five-year obesity incidence in the transition period between adolescence and adulthood: the National Longitudinal Study of Adolescent Health. Am J Clin Nutr. Sep 2004;80(3):569-575.

15. Norman JE, Bild D, Lewis CE, Liu K, West DS. The impact of weight change on cardiovascular disease risk factors in young black and white adults: the CARDIA study. Int J Obes Relat Metab Disord. Mar 2003;27(3):369-376 .

16. Colditz GA, Willett WC, Rotnitzky A, Manson JE. Weight gain as a risk factor for clinical diabetes mellitus in women. Ann Intern Med. Apr 1 1995;122(7):481-486.

17. Kopelman P. Health risks associated with overweight and obesity. Obes Rev. Mar 2007;8 Suppl 1:13-17.

18. Kozak AT, Daviglus ML, Chan C, Kiefe Cl, Jacobs DR, Jr., Liu K. Relationship of body mass index in young adulthood and health-related quality of life two decades later: the Coronary Artery Risk Development in Young Adults study. Int J Obes (Lond). Jun 152010. 
19. Huang TT, Kempf AM, Strother ML, et al. Overweight and components of the metabolic syndrome in college students. Diabetes Care. Dec 2004;27(12):3000-3001.

20. Burke JD, Reilly RA, Morrell JS, Lofgren IE. The University of New Hampshire's Young Adult Health Risk Screening Initiative. J Am Diet Assoc. Oct 2009;109(10):1751-1758.

21. Fernandes J, Lofgren IE. Prevalence of metabolic syndrome and individual criteria in college students. J Am Coll Health. Jan 2011;59(4):313-321 .

22. Lloyd-Jones DM, Wilson PW, Larson MG, et al. Lifetime risk of coronary heart disease by cholesterol levels at selected ages. Arch Intern Med. Sep 8 2003;163(16):1966-1972.

23. Tai ES, Goh SY, Lee JJ, et al. Lowering the criterion for impaired fasting glucose: impact on disease prevalence and associated risk of diabetes and ischemic heart disease. Diabetes Care. Jul 2004;27(7):1728-1734.

24. Hu FB, Willett WC. Optimal diets for prevention of coronary heart disease. JAMA. Nov 27 2002;288(20):2569-2578.

25. Anderson JW, Baird P, Davis RH, Jr., et al. Health benefits of dietary fiber. Nutr Rev. Apr 2009;67(4):188-205.

26. Johnson RK, Appel LJ, Brands M, et al. Dietary sugars intake and cardiovascular health: a scientific statement from the American Heart Association. Circulation. Sep 15 2009;120(11):1011-1020.

27. Haskell W, Lee, I-Min, Pate, Russell. Physical Activity and Public Health: Updated Recommendation for Adults from the American College of Sports Medicine and the American Heart Association. Medicine and Science in Sports and Exercise. 2007:1423-1443.

28. Lichtenstein $\mathrm{AH}$, Appel LJ, Brands $\mathrm{M}$, et al. Diet and lifestyle recommendations revision 2006: a scientific statement from the 
American Heart Association Nutrition Committee. Circulation. Jul 4 2006;114(1):82-96.

29. Leon AS, Sanchez OA. Response of blood lipids to exercise training alone or combined with dietary intervention. Med Sci Sports Exerc. Jun 2001;33(6 Suppl):S502-515; discussion S528-509.

30. Cheng C, Graziani C, Diamond JJ. Cholesterol-lowering effect of the Food for Heart Nutrition Education Program. J Am Diet Assoc. Dec 2004;104(12):1868-1872.

31. Thompson FE, Subar AF, Smith AF, et al. Fruit and vegetable assessment: performance of 2 new short instruments and a food frequency questionnaire. J Am Diet Assoc. Dec 2002;102(12):17641772.

32. Joint National Committee on Prevention D, Evaluation, and Treatment of High Blood Pressure. The Practical Guide: Identification, Evaluation, and Treatment of Overweight and Obesity in Adults. In: National Institute of Health; National Heart L, and Blood Institute ed. Bethesda, MD: North American Association for the Study of Obesity; 2000.

33. Lintsi M, Kaarma H, Kull I. Comparison of hand-to-hand bioimpedance and anthropometry equations versus dual-energy X-ray absorptiometry for the assessment of body fat percentage in 17-18-year-old conscripts. Clin Physiol Funct Imaging. Mar 2004;24(2):85-90.

34. Santee J. Accuracy and precision of the Cholestech LDX System in monitoring blood lipid levels. Am J Health Syst Pharm. Sep 15 2002;59(18):1774-1779.

35. Morrell JS, Lofgren IE, Burke JD, Reilly RA. Metabolic syndrome, obesity, and related risk factors among college men and women. $J \mathrm{Am}$ Coll Health. 2012;60(1):82-89.

36. Chatterjee S, Chatterjee P, Bandyopadhyay A. Validity of Queen's College Step Test for estimation of maximum oxygen uptake in female students. Indian J Med Res. Jan 2005;121(1):32-35. 
37. Chatterjee S, Chatterjee P, Mukherjee PS, Bandyopadhyay A. Validity of Queen's College step test for use with young Indian men. Br J Sports Med. Jun 2004;38(3):289-291.

38. McArdle WD, Katch FI, Pechar GS, Jacobson L, Ruck S. Reliability and interrelationships between maximal oxygen intake, physical work capacity and step-test scores in college women. Med Sci Sports. Winter 1972;4(4):182-186.

39. Blissmer B, Meebe, S, Riebe D, Greene, GW. An accurate and reliable field test for estimating health promotion effects on fitness: Predicting cardiorespiratory fitness in men using a simple three minute assessment. Paper presented at: 137th American Public Health Association Annual Meeting2009; Philadelphia, PA.

40. Myers EF. ADA Evidence Analysis Library. J Am Diet Assoc. May 2005;105(5 Suppl 1):S79.

41. Yamaoka S, Fujimoto M, Mori M, Mori H, Yamori Y. Risk reduction of lifestyle-related diseases in young adults on soy- or fish-rich traditional japanese meals. Clinical and Experimental Pharmacology and Physiology. 2007;34(November):S79-S81.

42. Cohen J. Statistical power analysis for the behavioral sciences 2nd ed. New Jersey: Lawrence Erlbaum; 1988.

43. Racette SB, Deusinger SS, Strube MJ, Highstein GR, Deusinger RH. Changes in weight and health behaviors from freshman through senior year of college. Journal of Nutrition Education and Behavior. Jan-Feb 2008;40(1):39-42.

44. Krauss RM, Winston M, Fletcher BJ, Grundy SM. Obesity : impact on cardiovascular disease. Circulation. Oct 6 1998;98(14):1472-1476.

45. Ha EJ, Caine-Bish N. Interactive introductory nutrition course focusing on disease prevention increased whole-grain consumption by college students. Journal of Nutrition Education and Behavior. Jul-Aug 2011;43(4):263-267. 
46. Ha EJ, Caine-Bish N. Effect of nutrition intervention using a general nutrition course for promoting fruit and vegetable consumption among college students. Journal of Nutrition Education and Behavior. Mar-Apr 2009;41(2):103-109.

47. Ha EJ, Caine-Bish N, Holloman C, Lowry-Gordon K. Evaluation of effectiveness of class-based nutrition intervention on changes in soft drink and milk consumption among young adults. Nutr J. 2009;8:50.

48. Kodama S, Tanaka S, Saito K, et al. Effect of aerobic exercise training on serum levels of high-density lipoprotein cholesterol: a meta-analysis. Arch Intern Med. May 28 2007;167(10):999-1008.

49. Fan AZ, Russell M, Naimi T, et al. Patterns of alcohol consumption and the metabolic syndrome. J Clin Endocrinol Metab. Oct 2008;93(10):3833-3838.

50. Lloyd-Richardson EE, Bailey S, Fava JL, Wing R. A prospective study of weight gain during the college freshman and sophomore years. Prev Med. Mar 2009;48(3):256-261.

51. Tirosh $A$, Shai I, Tekes-Manova $D$, et al. Normal fasting plasma glucose levels and type 2 diabetes in young men. $N$ Engl $J$ Med. Oct 6 2005;353(14):1454-1462.

52. Obarzanek E, Sacks FM, Vollmer WM, et al. Effects on blood lipids of a blood pressure-lowering diet: the Dietary Approaches to Stop Hypertension (DASH) Trial. Am J Clin Nutr. Jul 2001;74(1):80-89.

53. Miller ER, 3rd, Erlinger TP, Young DR, et al. Results of the Diet, Exercise, and Weight Loss Intervention Trial (DEW-IT). Hypertension. Nov 2002;40(5):612-618.

54. Jenkins DJ, Kendall CW, Marchie A, et al. Type 2 diabetes and the vegetarian diet. Am J Clin Nutr. Sep 2003;78(3 Suppl):610S-616S. 
55. Ribeiro Al, Lopes $\mathrm{C}$, Barros $\mathrm{H}$, de Pina MD. After a quarter of century, reduction in Coronary Heart Disease Mortality bypassed young adult males in Portugal. Int J Cardiol. Sep 82011.

56. O'Flaherty M, Ford E, Allender S, Scarborough P, Capewell S. Coronary heart disease trends in England and Wales from 1984 to 2004: concealed levelling of mortality rates among young adults. Heart. Feb 2008;94(2):178-181.

57. Magnussen CG, Niinikoski $H$, Juonala $M$, et al. When and how to start prevention of atherosclerosis? Lessons from the Cardiovascular Risk in the Young Finns Study and the Special Turku Coronary Risk Factor Intervention Project. Pediatr Nephrol. Aug 302011.

58. Mokdad AH, Marks JS, Stroup DF, Gerberding JL. Actual causes of death in the United States, 2000. JAMA. Mar 10 2004;291(10):12381245.

59. Larson NI, Neumark-Sztainer DR, Harnack LJ, Wall MM, Story MT, Eisenberg ME. Fruit and vegetable intake correlates during the transition to young adulthood. Am J Prev Med. Jul 2008;35(1):33-37.

60. Adeyo O, Horn PJ, Lee $S$, et al. The yeast lipin orthologue Pah1p is important for biogenesis of lipid droplets. J Cell Biol. Mar 21 2011;192(6):1043-1055.

61. Rodney G. Bowden PD. Lipid Levels in a Cohort of Sedentary University Students. The Internet Journal of Cardiovascular Research. $2005 ; 2(2)$.

62. Albert CM, Gaziano JM, Willett WC, Manson JE. Nut consumption and decreased risk of sudden cardiac death in the Physicians' Health Study. Arch Intern Med. Jun 24 2002;162(12):1382-1387.

63. Hu FB, Bronner L, Willett WC, et al. Fish and omega-3 fatty acid intake and risk of coronary heart disease in women. JAMA. Apr 10 2002;287(14):1815-1821. 
64. Joshipura KJ, Hu FB, Manson JE, et al. The effect of fruit and vegetable intake on risk for coronary heart disease. Ann Intern Med. Jun 19 2001;134(12):1106-1114.

65. Dauchet L, Amouyel P, Hercberg S, Dallongeville J. Fruit and vegetable consumption and risk of coronary heart disease: a meta-analysis of cohort studies. Journal of Nutrition. Oct 2006;136(10):2588-2593.

66. Liu S, Stampfer MJ, Hu FB, et al. Whole-grain consumption and risk of coronary heart disease: results from the Nurses' Health Study. Am J Clin Nutr. Sep 1999;70(3):412-419. 


\section{APPENDICES}

\section{A. REVIEW OF LITERATURE}

\section{Introduction}

Coronary heart disease (CHD) caused about one in six deaths in the United States (US) in $2007 .{ }^{1}$, making it the number one cause of death in the US $^{2}$, and the fifth leading cause of death in young adults. ${ }^{2}$ Signs of atherosclerosis, the arterial plaque build-up that causes $\mathrm{CHD},{ }^{67}$ can begin as early as adolescence ${ }^{9,67}$ and track into adulthood. ${ }^{9}$ Traditional CHD risk factors can also be used to estimate risk of $\mathrm{CHD}^{68}$. These risk factors include elevated plasma total cholesterol (TC), low-density lipoprotein cholesterol (LDL-C), triacylglycerol (TAG), low high-density lipoprotein cholesterol (HDLC), physical inactivity, overweight and obesity, and diabetes mellitus. ${ }^{68}$ Impaired fasting plasma glucose is another $\mathrm{CHD}$ risk factor. ${ }^{7}$ Prevalence of these risk factors is evident in college students across the country. ${ }^{19-21,61}$ Although there is limited research on the impact of nutrition and physical activity interventions on CHD risk factors in college students, research shows that these risk factors can be improved by changing $\operatorname{diet}^{6,28}$ and increasing physical activity ${ }^{29}$ in other populations.

\section{Coronary Heart Disease Risk and Treatment}

Contributions of poor diet quality and inactivity 
The National Cholesterol Education Program Adult Treatment Panel III (NCEP ATP III) provides a population based approach to reducing heart disease through healthy lifestyle habits called therapeutic lifestyle changes (TLC), including adopting a healthy diet and increased physical activity. ${ }^{7}$ These two lifestyle changes should be addressed in interventions because many Americans are not meeting national guidelines for nutrition ${ }^{69}$ and physical activity. ${ }^{70}$

Diet quality indices like the Healthy Eating Index (HEI) measure adherence to dietary recommendations, specifically the Dietary Guidelines for Americans. Briefel et al ${ }^{69}$ examined the dietary quality of participants in the National Health Examination Survey (NHANES) 1999-2000 using the HEI. At that time, the results indicated that only $10 \%$ of Americans had good diets according to the HEI (a score of 80 out of 100 ), $75 \%$ needed improvement (a score of $51-80$ ) and $16 \%$ had poor diets (a score of 50 or less). Improving nutrition is one method of decreasing preventable deaths. ${ }^{71}$ Danaei et al, ${ }^{71}$ using NHANES and other nationally representative survey data, reported that low intake of fruits and vegetables responsible for 55,000 annual deaths, high intake of trans fatty acids were responsible for 82,000 annual deaths, and that low intake of omega-3 fatty acids were responsible for 84,000 annual deaths.

Physical activity is important for cardiovascular health; the American College of Sports Medicine provides guidelines for physical activity based on research showing a dose response relationship between physical activity and 
cardiovascular diseases (like CHD) and premature mortality. ${ }^{27}$ Unfortunately, in 2001, less than half of Americans (45.4\%) met these recommendations, and about a quarter (26.0\%) did no leisure time physical activity at all. ${ }^{70}$ The cost of this inadequate physical activity is high; in 2007 , Deneai et $\mathrm{al}^{71}$ found that physical inactivity was responsible for one in 10 deaths in the United States.

Types of primary, secondary and tertiary CHD treatments and their cost Treatment of CHD can be primary, defined as occurring before pathological onset, secondary, which takes place after pathological onset but before clinical signs appear, and tertiary, which is implemented after clinical diagnosis occurs. If CHD risk is reduced in young adults and therefore future $\mathrm{CHD}$ incidence is reduced, health care costs related to treatment and surgery may significantly decrease. ${ }^{72}$ Secondary interventions often are initiated in older adults and can be difficult and expensive to implement. Common secondary interventions for heart disease include diet and exercise as well as lipid-lowering medications like statins. Dietary modifications may be particularly challenging for older adults, since food habits maintained over a lifetime may be more difficult to change ${ }^{73}$ Compliance with structured exercise interventions can be difficult, ${ }^{74}$ and maintenance is hard to achieve, adherence rates in have dropped as low as $50 \%$ after six months with a three day a week program. ${ }^{75}$ Medications can be expensive; if all people aged 35-85 years were to be placed on recommended statin doses, it would cost $\$ 5.9$ billion per 
year. ${ }^{76}$ Statins also have side effects, most frequently myopathies that include muscle pain and elevated creatine phosphokinase. ${ }^{77}$

Tertiary interventions are even more expensive. The five-year costs of common surgical interventions for CHD; angioplasty and coronary artery bypass surgery, are $\$ 52,930$ and $\$ 58,498$, respectively. ${ }^{78}$ Over half of the hospital stays due to atherosclerosis were for those receiving a coronary artery bypass surgery procedure ${ }^{68}$ Coronary atherosclerosis was the most expensive condition treated in hospitals in the US in 2004, costing the US over $\$ 44$ billion. ${ }^{68}$ Increasing utilization of primary prevention could reduce the number of people needing these procedures. This could save money, decrease the cost of health insurance, and improve quality of life and productivity for people of all ages. Primary prevention is a cost-effective way to reduce risk of $\mathrm{CHD}$ before disease onset, and before medications and/or surgery become necessary. ${ }^{79}$ Young adulthood is an ideal time to initiate healthy lifestyle changes, as lifestyle habits have not yet been established and will likely carry through to adulthood.

\section{Reason for Intervention in College Students}

College students are an important population to research because the transition from adolescence to adulthood comes with an important shift in responsibility for food choices. Most college students leave the controlled food environment of their childhood homes and begin making their own choices in a 
buffet-style dining hall ${ }^{11}$ with unlimited food availability. This sudden food independence, along with the heavy caloric load of binge drinking ( $44 \%$ of college students) ${ }^{12}$ creates an environment where college students gain weight about six times faster than the general population, ${ }^{13}$ and $35 \%$ are overweight or obese. ${ }^{8}$ The 2010 Dietary Guidelines prioritize early nutrition intervention since eating patterns often track into later life..$^{80}$

Weight status, as measured by body mass index (BMI), in young adults is negatively correlated with self-reported health related quality of life 20 years later ${ }^{18}$ and is positively associated with risk of developing CHD. ${ }^{17}$ Compared with normal-weight college students, overweight students had higher TAG, TC and LDL-C concentrations. ${ }^{19}$ Weight gain in college students is of concern, because students who gain weight in college tend to stay overweight. ${ }^{14}$ Weight gain during this transition period is important to address because obesity may soon surpass cigarette smoking as the leading cause of preventable death in the US. ${ }^{81,82}$

\section{Physical Activity}

Another change college students experience as they progress from adolescence is a decrease in structured physical activity. ${ }^{83}$ In adolescents, the greatest declines in physical activity were from ages 15 through $18{ }^{83}$ From ages 12-21 both regular and vigorous physical activity and strengthening physical activity patterns declined, with a continued drop during young 
adulthood (18-29 years old).$^{83}$ In an older cohort of 1710 adolescents examined for five years from high school to college age, students decreased moderate to vigorous physical activity $(p<0.001)$ and increased leisure time computer use $(p<0.001) \cdot{ }^{84}$ Out of over 5,000 college students examined in three colleges in North Carolina, 39\% reported complete physical inactivity. ${ }^{85}$ The result of these trends as well as other lifestyle factors is that college students are not meeting physical activity guidelines. ${ }^{86}$

\section{Dietary quality}

Of the 4,609 undergraduate college students surveyed using questionnaires by the National College Health Risk Behavior Survey in 1995, only about one quarter reported consuming the recommended five servings of fruits and vegetables daily. ${ }^{86}$ Using 24 -hour food recalls, a more robust method of dietary data collection, longitudinal food consumption patterns were examined in young adults from the Bogalusa Heart Study from 1973-1991. ${ }^{87}$ The researchers analyzed nutrient density using scores ranging from $1-5 .{ }^{87}$ Each food consumed from each of the five major foods groups contributed one point to the score (using the 1992 Food Guide Pyramid) ${ }^{87}$ This nutrient dense score was related to overall diet quality, and results demonstrated a large decrease in diet quality from childhood to young adulthood. ${ }^{87}$ At age 10 years, $50 \%$ of children had a diet quality score of five, but at young adulthood, only $19 \%$ received a diet quality score of five. ${ }^{87}$ Intake of milk and total dairy 
decreased from childhood to young adulthood, and many young adults didn't consume recommended amounts of fruit $(83 \%) .{ }^{87}$

Diet quality is also related to risk factors for CHD, like elevated glucose and TC and low HDL-C. ${ }^{88}$ In a Australian nationally representative sample of 11,247 participants $\geq 25$ years old, diet quality was associated with CHD risk. ${ }^{88}$ Diet quality was measured using a 10 point scale for each of 13 items, in which more points indicated a closer adherence to that particular Australian government guideline ${ }^{88}$ After adjusting for relevant covariates, diet quality in both men and women was associated with lower TC and glucose. ${ }^{88}$ Since poor dietary quality is associated with $\mathrm{CHD}$ risk factors ${ }^{88}$ and college students show poor dietary quality, interventions are needed to improve dietary quality in college students.

\section{Risk Factors in College Students}

In college, young adults, defined here as ages 18 to 24 , are transitioning from adolescence to adulthood. Weight gain during this time can result in dyslipidemia, ${ }^{15}$ including low HDL-C, and elevated LDL-C, TAG and glucose.

Risk factors can be measured in college-aged populations to estimate future risk of $\mathrm{CHD} .^{19,20,61} \mathrm{~A}$ cross-sectional study of $189 \mathrm{URI}$ first year students found that elevated TAG concentrations (17.5\%) and low HDL-C concentrations $(20.1 \%)$ were the most prevalent biochemical CHD risk 
factors. ${ }^{21}$ This is in comparison to similar research completed at other universities. In Waco, Texas at Baylor University, the most prevalent risk factors of 108 sedentary students in a health class were elevated LDL-C (41.3\%) and low HDL-C (38.8\%). ${ }^{61}$ In Durham, New Hampshire at the University of New Hampshire, researchers looked at the diet and health indicators of 1,701 college students aged $18-24$ and found that $53 \%$ of students had elevated LDL-C and $47 \%$ had high systolic blood pressure. ${ }^{20}$ In contrast to these findings, in Lawrence, Kansas at Kansas University, low HDL-C (13.5\%) and high TC (11.7\%) were most prevalent in 18-24 year old students, $163 .{ }^{19}$ Abnormal lipid concentrations present early in life are dangerous because these values tend to maintain or even worsen as one ages (4). They can be used to estimate future CHD risk in young adults who show signs of atherosclerosis (32). Young adults show signs of atherosclerosis and their future $\mathrm{CHD}$ risk can be estimated from risk factors like abnormal lipids. ${ }^{89}$

\section{Risk Factors for CHD: TC, LDL-C, HDL-C, TAG and Glucose; Metabolism and Impact}

\section{Overview of lipoprotein metabolism}

Lipid absorption and transport 
The major classes of dietary fats are of TAG, phospholipids and sterols, though the majority are TAG. Initial digestion occurs in the mouth through the action of lingual lipase and the stomach with the action of gastric lipase..$^{90,91}$ The lipases hydrolyze TAG into diglycerides and free fatty acids, ${ }^{90}$ which combine with phospholipids and dietary cholesterol to form a lipid emulsion. ${ }^{92}$ When fat empties into the small intestine, cholecystokinin is released, which stimulates the gall bladder to release bile, emulsifying the fat in the small intestine into fine lipid droplets. ${ }^{90,93}$ Pancreatic lipase, secreted into the duodenum, acts on the lipid emulsion in the lumen in the small intestine, releasing more fatty acids from the glycerol backbone. ${ }^{90,91}$ The result is a mix of monoacyglcerols, diacylglycerols, and free fatty acids. ${ }^{91}$ Phosholipase $A_{2}$ is secreted as a zymogen, and once activated by trypsin, hydrolyzes phospholipids in the small intestine. ${ }^{90}$ Any cholesterol ester (CE) from the diet is hydrolyzed to free cholesterol and a fatty acid by cholesterol esterase secreted by the pancreas to enable absorption by the small intestine ${ }^{90,91}$ To cross the unstirred water layer of the enterocytes cells, the resulting lipid products are packaged with bile salts into mixed micelles. ${ }^{90}$

Once in the endoplasmic reticulum of the enterocytes, acyl CoA: cholesterol acyltransferase, isoform 2 reesterifies cholesterol (REF). Microsomal triglyceride transfer protein transfers TAG into chylomicrons (CM), ${ }^{92}$ and TAG, phospholipids and CE are all packed into TAG rich CM with a particle of apolipoprotein B48. ${ }^{90,91,94,95}$ 
Lipoprotein lipase (LPL) with apolipoprotein Cll as a co-factor, hydrolyzes the TAG and CE in the core of the CM into free fatty acids, glycerol, and unesterified cholesterol. The hydrolyzed TAG is sent mainly to adipose and muscle tissue for storage or is oxidized and used for energy, respectively, while the CE are sent to cells to be used in plasma membranes for steroid hormone or in the liver for bile acid synthesis. ${ }^{96}$ This hydrolysis is the first step in the delipidation cascade,${ }^{95}$ and results in a chylomicron remnant (CM-R), which is taken up by a low-density lipoprotein-like receptor protein on the liver. ${ }^{94}$

After the CM-R attached to the receptor protein on the liver and is brought into the hepatocyte via endocytosis, it is broken down into it's component parts including fatty acids, free cholesterol and CE. ${ }^{91}$ Very-low density lipoproteins are produced from endogeonous TAG in the smooth endoplasmic reticulum of the liver. ${ }^{91}$ The VLDL is transferred to the Golgi apparatus and excreted with apolipoproteins $\mathrm{A}-100, \mathrm{Cl}$, and $\mathrm{E} \cdot{ }^{91} \mathrm{At}$ extracellular cites, lipoprotein lipase hydrolyzes some TAG in the VLDL, turning the VLDL into smaller VLDL remnants also known as intermediate density lipoproteins (IDL). ${ }^{94}$ At this point, the LDL receptor (LDLR) on the liver's surface may uptake the IDL via apoliprotein $\mathrm{E}^{94}$ or the TAG in the IDL may be hydrolyzed by hepatic lipase, producing an LDL, ${ }^{94}$ and the cholesterol contained in the LDL particle is then distributed to the periphery. The LDLR on the liver may uptake the LDL through interacting with apolipoprotein B-100, but 
if it does not, the LDL remains in circulation, depositing cholesterol in the periphery. Some of the cholesterol deposited in the intima-media space of peripheral tissues by the LDL may become oxidized, which increases the likelihood that the cholesterol will be taken up by a macrophage and become a foam cell. ${ }^{94}$ This process of foam cell formation can contribute to the formation of atherosclerotic plaque ${ }^{94}$ (figure 3).

Figure 3: Atherosclerosis formation available at http://www.virtualsciencefair.org/2009/hsuj9j2/background.htm taken from http://dakappa.com/health/reduction/reduction.htm

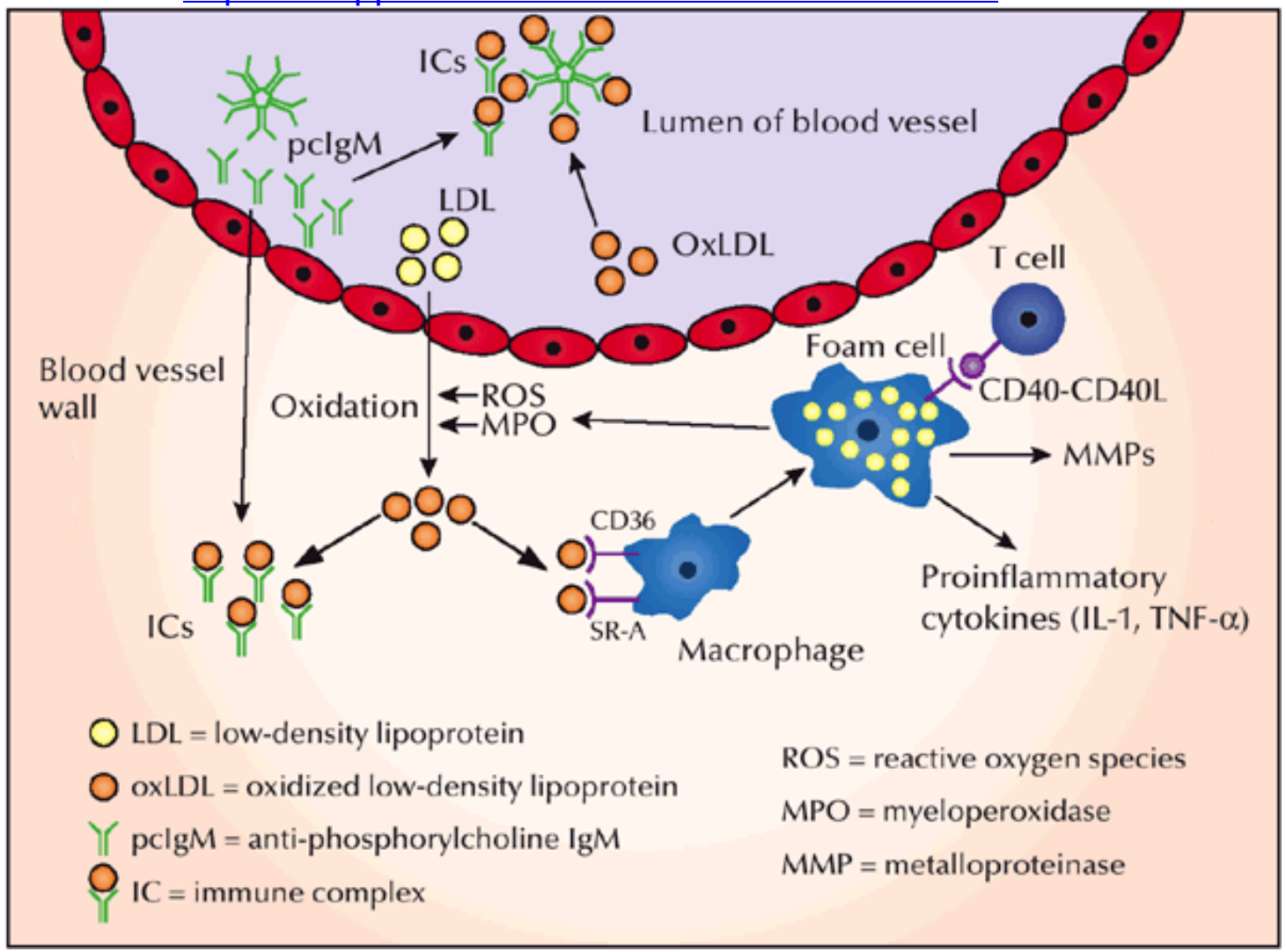

Reverse cholesterol transport

Reverse cholesterol transport is a major mechanism by which HDL particles remove cholesterol from the periphery, preventing plaque formation and atherosclerosis. ${ }^{94}$ Nascent HDL particles are made in the liver and 
intestine and is composed of phospholipids and apolipoprotein A-1 (apoA-1) and contains little cholesterol. ${ }^{94}$ The HDL particle forms a mature spherical particle when lecithin-cholesterol acyl transferase (LCAT) and its cofactor apoA-1 transfer a free fatty acid from lecithin..$^{94}$ The nascent HDL acquires esterified cholesterol in the periphery through the action of $A B C 1$ transporter protein. ${ }^{94}$ Cholesterol ester transfer protein (CETP) transfers half of the CE to the apo containing lipoproteins (VLDL, IDL and LDL) and when the HDL loses its $\mathrm{CE}$, it returns to the plasma and brings back more cholesterol. ${ }^{94}$ The $\mathrm{CE}$ obtained from HDL is used to form steroid hormones and for bile acid synthesis in the liver, removing it from circulation. ${ }^{94}$ The removal of cholesterol from the periphery through reverse cholesterol transport explains the cardioprotective impact of high concentrations of HDL-C. ${ }^{94}$ The other half of the $\mathrm{CE}$ in mature $\mathrm{HDL}$ are taken into the liver through selective uptake by the scavenger receptor B1 (SR-B1). When the whole HDL particle is taken up, the hepatic endosomes and lysosomes degrade it into it's component parts ${ }^{94}$

TAG

Risk factors, like elevated TAG and low HDL-C can predict future risk of $\mathrm{CHD}^{7,9,97}$ In western populations, individuals in the top third of TAG concentrations are $72 \%$ more likely to get CHD than those in the lowest third, even when adjusted for age, sex, smoking, and lipid concentrations ${ }^{98}$ A metaanalysis of 20 studies involving over 10,000 incidences of heart disease in 
over 250,000 people showed significant moderate associations between TAG values and $\mathrm{CHD}$ risk. ${ }^{98} \mathrm{An}$ increase in TAG of $88 \mathrm{mg} / \mathrm{dL}$ increases a man's risk of $\mathrm{CHD}$ by $34 \%$ and a woman's by $71 \%{ }^{97}$

An analysis of over 300,000 people found evidence consistent with a causal role for TAG mediated pathways in CHD. ${ }^{99}$ This may be due to the premature atherosclerosis found in those with elevated TAG, or to the elevated TAG, which could remodel LDL and HDL particles, making them smaller and denser. ${ }^{99}$ This greater density would increase the atherogenicity of LDL and may impair HDL function. ${ }^{99}$ About half the decrease in $\mathrm{CHD}$ deaths in the US from 1980-2000 is attributed to improvements in major risk factors like TAG and HDL-C. ${ }^{72}$ Lifestyle improvements like changes in diet quality can decrease TAG concentrations. $^{100,101}$

Elevated TAG concentrations are found in $17.5 \%$ of first year University of Rhode Island (URI) students. ${ }^{21}$ College students' dietary intakes tend to increase TAG via increased consumption of alcohol ${ }^{102,103}$ and added sugars. ${ }^{104,105}$ Maintaining recommended TAG concentrations is important for young adults, given the negative impact on future health, since TAG is an independent $\mathrm{CHD}$ risk factor. ${ }^{97}$

$H D L-C$

Low HDL-C is an independent predictor of heart disease and plays an important role in reverse cholesterol transport as an antioxidant and anti- 
inflammatory agent. ${ }^{106-108}$ The most recent recommendations by the third report of the National Cholesterol Education Panel, Adult Treatment Panel (NCEP ATP III) define low HDL-C as $<40 \mathrm{mg} / \mathrm{dL}$. An HDL-C of $\geq 60 \mathrm{mg} / \mathrm{dL}$ is considered heart protective, as it was shown to be associated with a reduced risk for $\mathrm{CHD}^{7}$ In a longitudinal study where 5,345 men and women, aged 3074 were followed for 12 years, CHD risk was higher in those with low HDL-C ( $<35 \mathrm{mg} / \mathrm{dL}$, using ATP II criteria) and lower among those with $\geq 60 \mathrm{mg} / \mathrm{dL}$ HDL-C. ${ }^{109}$ More specifically, the results from the Helsinki Heart Study and the Veterans Affairs HDL Intervention Trial show that increasing serum HDL-C by $1 \%$ is associated with a decrease in CHD risk by $3 \% .{ }^{110}$

Nutrition education can impact HDL-C; a study of 100 African American men and women aged 35-75 years old showed that 12 weeks of diet and physical activity education can lead to a $5.11 \pm 0.9 \mathrm{mg} / \mathrm{dL}$ increase in HDL-C $(p<0.01) .{ }^{111}$ This intervention taught participants how to decrease saturated fat and cholesterol, increase fruits and vegetables and fiber, limit salt and alcohol and maintain moderate physical activity. ${ }^{111}$ Aerobic training can also increase HDL-C; a review of 51 studies examining the response of blood lipids to exercise training concluded that the most common response to aerobic exercise training was an increase in HDL-C. ${ }^{29}$ 
Total cholesterol is predictive of $\mathrm{CHD}^{112}$ and can effectively stratify men and women of all ages by remaining lifetime risk for $\mathrm{CHD}^{22}$ Desirable TC is defined as $<200 \mathrm{mg} / \mathrm{dL}$, borderline high is considered $200-240 \mathrm{mg} / \mathrm{dL}$, and high cholesterol is considered anything $240 \mathrm{mg} / \mathrm{dL}$ or higher by the NCEP ATP III. ${ }^{7}$ Based on data from NHANES $2005-2008,8.5 \%$ percent of $12-19$ year olds have elevated TC ( $>200 \mathrm{mg} / \mathrm{dL}$ ), and $16.2 \%$ of adults $\geq 20$ years old have a TC $\geq 240 \mathrm{mg} / \mathrm{dL} .{ }^{1}$ In 7,288 Framingham Heart Study participants, those with elevated TC had a 1.5-2 fold greater absolute lifetime risk of CHD when compared with those with desirable TC concentrations. ${ }^{22}$ Clinical end points have also been examined, and in a case-controlled prospective sample of 492 men, as TC went up, so did risk for myocardial infarction (RR 1.86 in highest quintile, $p=0.025) .{ }^{113} \mathrm{~A}$ meta-analysis of 41 prospective, international and randomized controlled trials showed that by reducing serum cholesterol $10 \%$ at age 40 , the risk of ischaemic heart disease is reduced by $50 \% .{ }^{114}$

Behaviorally based nutrition education can impact TC concentrations. Hypercholesterolemic adults in the intervention group of the Food for Heart program decreased their TC by $15.47 \pm 25.14$ in four months $(p<0.05) .{ }^{115}$ Young adults show prevalence of elevated TC, ${ }^{1}$ which is concerning because as total cholesterol rises, so does lifetime risk of $\mathrm{CHD}$ for men and women of all ages. $^{22}$ 
$L D L-C$

Elevated LDL-C is the primary target of CHD prevention therapy according to the NCEP ATP III. ${ }^{7}$ Lowering LDL-C reduces the risk of coronary events, as evidenced by many randomized controlled trials. ${ }^{116-118}$ Low-density lipoprotein cholesterol can be measured in college populations to estimate future risk of $\mathrm{CHD} .{ }^{19,20,61}$ Two universities found that the most prevalent risk factors in their colleges were elevated LDL-C; at Baylor University, $41 \%$ of sedentary students in a health class had elevated LDL-C and $53 \%$ of the 1,701 students examined at the University of New Hampshire had elevated LDL-C. ${ }^{20,61}$

Dietary modifications are an effective way to decrease LDL-C in young adults. ${ }^{119}$ When a high saturated fat diet was replaced with either a NCEP Step 1 diet or a high MUFA diet in 31 healthy men $<30$ years old, LDL-C decreased during both the Step 1 diet and the high MUFA diet. ${ }^{119}$ This may be because healthy fats have a beneficial effect on LDL-C by reducing CETP activity. ${ }^{119}$ Cholesterol ester transfer protein activity is activated by sterol regulatory binding protein 1 (SREBP1). ${ }^{120} \mathrm{An}$ isoform of this transcriptional factor, SREBP2, regulates the low-density lipoprotein receptor (LDLr), which is shown to be up-regulated simultaneously. ${ }^{121}$ The up-regulation of LDLr increases the uptake of LDL via LDLr into the liver, where it is broken down into triacylglycerols (TAG), cholesterol ester (CE), and phospholipids, and then the CE can be excreted in the feces. Cholesterol ester transfer protein is a 
plasma glycoprotein that catalyzes the transfer of CE from HDL to apolipoproteinB (apoB) containing lipoproteins like very low density lipoproteins (VLDL) and intermediate density lipoproteins (IDL). Lipoprotein lipase hydrolyzes the TAG from these lipoproteins, which will become LDL. The down-regulation of CETP causes a diminished transfer of CE to apoB containing lipoproteins, and decreases the cholesterol content of LDL, reducing plasma LDL-C in the body. This mechanism is also presented in figure 4.

Figure 4: Mechanism of action for the down-regulation of CETP

\section{mechanism of action}

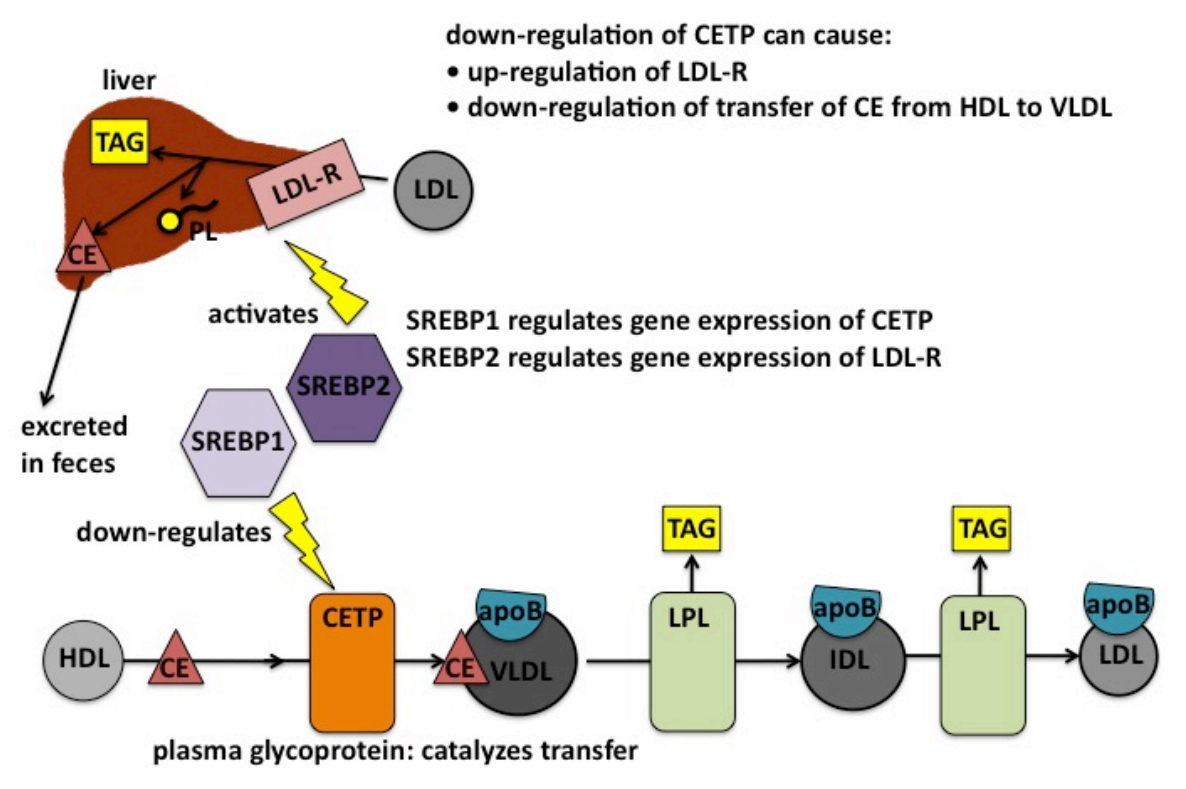




\section{Overview of glucose metabolism}

Carbohydrates are consumed as disaccharides, oligosaccharides, and polysaccharides, and in the body are converted primarily into glucose, but also fructose and galactose in smaller amounts. ${ }^{90}$ The sodium glucose transporter 1 uses adenine triphosphate (ATP) to actively transport glucose through the mucosal cells of the small intestine.${ }^{91}$ Glucose is transported in the body by a family of 12 isoforms of protein carriers, called glucose carriers (GLUT) $\cdot{ }^{91}$ The GLUT2 carrier in the serosal membrane transports about $60 \%$ of the absorbed glucose into circulation. ${ }^{91}$ Smaller amounts leak back into the intestinal lumen, diffuse through the membrane into circulation, and are used by the mucosal cell for energy ${ }^{91}$

Glucose is the primary fuel the human body uses for energy, as all human tissues can utilize glucose to produce energy, and certain specialized cells can only use glucose.$^{90}$ In order to maintain blood glucose concentrations within strict ranges so that the body has a consistent supply, glucose is produced from exogenous and endogenous sources. ${ }^{90}$ The liver plays an important role in glucose homeostasis. Liver cells can completely oxidize glucose for energy, store glucose as glycogen for future use, or break it down

to biosynthesize either fatty or amino acids. ${ }^{90}$ When blood glucose is low, the liver can degrade glycogen or perform gluconeogensis. ${ }^{90}$ In the heart and skeletal muscle, glucose can also be stored as glycogen or completely oxidized. Neither the heart or skeletal muscles can release glucose into 
circulation. ${ }^{90}$ Adipose tissues can completely oxidize glucose, partially degrade it to provide glycerol for TAG synthesis, or when carbohydrate intake is high, store the glucose. ${ }^{90}$

Storage of glucose involves glucose being metabolized to acetyl CoA which is used to synthesize fatty acids that can be stored in the adipose tissue, and released to the circulation as fuel when the body requires energy. ${ }^{90}$ The brain, normally a glucose-dependent tissue, can completely oxidize glucose, but stores very little glucose, and so is dependent upon a consistent supply from circulation. ${ }^{90}$ Red blood cells metabolize glucose to lactate and release it into circulation since they do not possess the mitochondria needed for complete oxidation. ${ }^{90}$

Glycolysis is the first step of intracellular glucose oxidation. It breaks glucose down into NADH and pyruvate. ${ }^{122}$ Pyruvate can be transported into the mitochondria, where it is oxidized by the tricarboxylic acid cycle into $\mathrm{CO}_{2}$, $\mathrm{H}_{2} \mathrm{O}, \mathrm{NADH}$ and $\mathrm{FADH}{ }_{2}{ }^{122}$ The $\mathrm{NADH}$ and $\mathrm{FADH} \mathrm{H}_{2}$ are used in oxidative phosphorylation by the electron transport chain and provide energy for creation of ATP, ${ }^{122}$ which provides energy for all bodily functions. Four enzyme complexes along with ubiquinione and cytochrome c work together to keep electrons flowing through the mitochondrial electron transport chain (Figure 5). NADH donates electrons to complex I (NADH: ubiquionone oxidoreductase) and ultimately to ubiquinone, which can be reduced by complex II (succinate:ubiquinone oxidoreductase) and glycerol-3-phosphate 
dehydrogenase. ${ }^{122}$ The electrons from reduced ubiquinone are then transferred to complex III (ubiquinol:cytochrome c oxidoreductase) and electron transport then continues through cytochrome c, complex IV (cytochrome c oxidase) and molecular oxygen. The transfer of electrons through complexes I, III and IV creates a protein gradient driving the fifth complex which is an ATP synthase. ${ }^{122}$ This ATP production fuels metabolic processes throughout the body.

Figure 5: Production of superoxide by the mitochondrial electron-transport chain $^{122}$

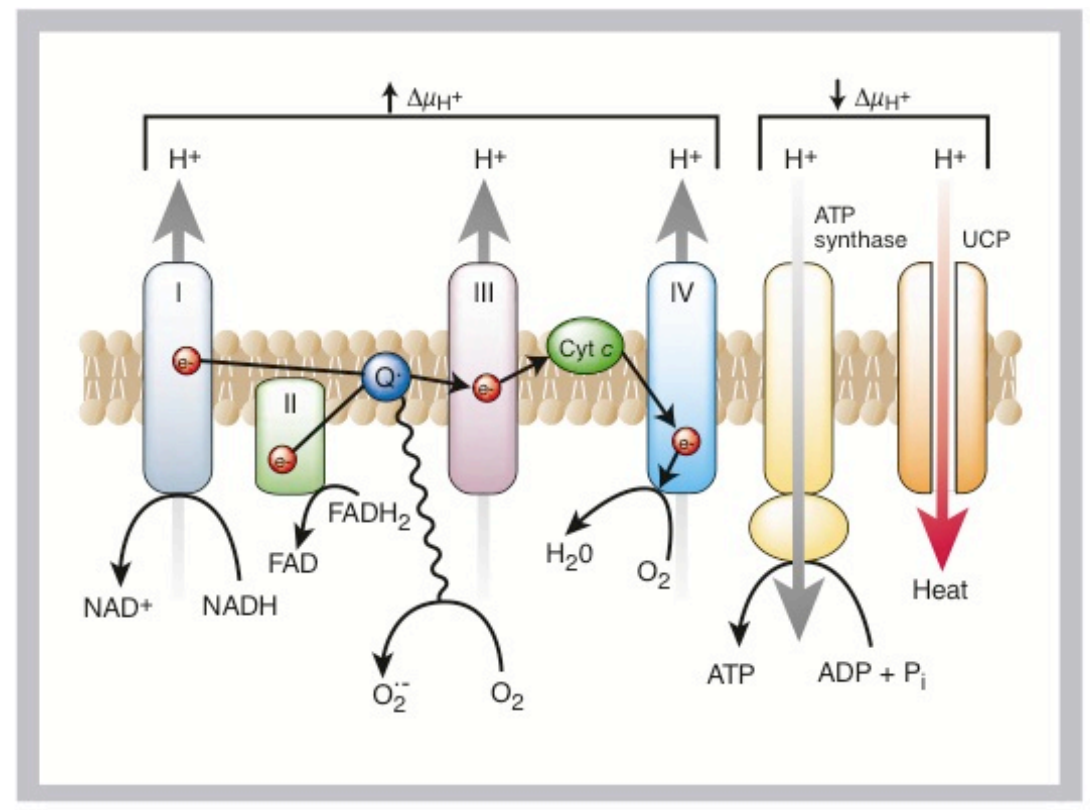

\section{Plasma Glucose}

Elevated plasma glucose, or hyperglycemia, is largely responsible for the increased morbidity and mortality from CVD seen in those with diabetes. ${ }^{4}$ This danger is high, at least $65 \%$ of those with diabetes die from either heart 
disease or stroke. ${ }^{68}$ In 2002, the ATP III noted impaired fasting glucose (110$125 \mathrm{mg} / \mathrm{dL}$ ) as an emerging CHD risk factor. ${ }^{7}$ The ATP III identified impaired fasting glucose as a component of the metabolic syndrome that signifies the need for more intensive lifestyle therapies. ${ }^{7}$ In 2003, the criteria for impaired fasting glucose dropped to $100-125 \mathrm{mg} / \mathrm{dL}$, as evidence showed this lower level would improve the test's ability to predict future diabetes. ${ }^{123}$ While it may have improved the ability to predict diabetes, it made it more difficult to use fasting glucose to predict CHD risk. Results from a longitudinal study of older adults led the authors to posit that impaired fasting glucose (100-125 mg/dL) no longer predicts cardiovascular risk on its own, even though individuals who develop diabetes still showed increased risk of CVD. ${ }^{124}$ In another study, those who progressed to diabetes were removed from the analysis, and impaired glucose tolerance was not associated with a CHD risk profile. ${ }^{125}$ Since elevated fasting glucose predicts diabetes, ${ }^{126}$ and diabetes is associated with elevated risk of $\mathrm{CHD},{ }^{127,}{ }^{128}$ examining fasting plasma glucose does indicate eventual risk of CHD, through the metabolic abnormalities associated with diabetes. ${ }^{122}$

A possible mechanism for this relationship is that hyperglycemia is a trigger for inflammatory responses. There are four main hypotheses about how hyperglycemia causes the complications (like CHD) that occur in diabetics. These include: increased hexosamine pathway flux, increased polyol pathway flux, increased advanced glycation end-product formation, and activation of 
protein kinase $C{ }^{122}$ One main hypothesis links all four of these; the mitochondrial electron transport chain overproduces superoxide. ${ }^{122}$ This overproduction leads to many downstream effects in the body, including a decrease in glycerolaldehyde-3-phosphate dehydrogenase activity, overactivation of protein kinase $\mathrm{C}$, and increased fructose-6-phosphate, all of which can lead to insulin resistance, further aggravating hyperglycemia. ${ }^{129}$

Impact of Lifestyle Changes on Glucose Concentrations

Diet and physical activity impact plasma glucose. ${ }^{130-132}$ In 11,247 Australian adults, high diet quality was associated with lower fasting plasma glucose. ${ }^{88}$ Six months of a monounsaturated fatty acid (MUFA) rich diet (>20\% of energy) in young, normoglycemic, overweight and obese adults showed that a higher intake of nuts and legumes predicted fasting glucose and may improve glucose homeostasis long term. ${ }^{133}$ Another intervention with a similar population saw a drop of $3.6 \pm 7.2 \mathrm{mg} / \mathrm{dL}$ of glucose after six months of a weekly small group ( 20 people) weight loss dietary intervention. ${ }^{131}$ Adults are not the only ones who can be impacted through lifestyle changes, younger groups can also be impacted. ${ }^{132}$ A multi-component model of nutrition and lifestyle intervention in Asian Indian adolescents (aged 15-17) showed a decrease in fasting blood glucose $(p=0.05,95 \% \mathrm{Cl}=-0.09,5.00)$ in the intervention group compared with a control group. ${ }^{132}$ 
Since elevated plasma glucose is a risk factor for diabetes, ${ }^{126}$ and more than half of those with diabetes die from $\mathrm{CHD},{ }^{68}$ lifestyle changes which can lower plasma glucose should be implemented before the adverse metabolic changes resulting from elevated plasma glucose can occur.

\section{Lifestyle changes recommended by Health It Up Intervention that can improve risk factors for CHD}

\section{Primary prevention}

Improving CHD risk factors through lifestyle change can attenuate the development of atherosclerosis and is an effective way to prevent $\mathrm{CHD}^{7,9}$ Since heart healthy diets often restrict many foods, patients frequently have difficulty complying with these diets. ${ }^{134} \mathrm{~A}$ useful alternative includes dietary change that relies on adding healthy whole foods to a self-selected or prescribed diet. ${ }^{134}$ Some of these self-selected changes could include those recommended to decrease $\mathrm{CHD}$ risk by Hu and Willet. ${ }^{24}$ This review states that there is compelling evidence to demonstrate that at least three dietary strategies can prevent CHD. ${ }^{24}$ These include; 1) maintaining a diet high in nuts, fruits, vegetables and whole grains and low in refined grains, 2) increasing intake of omega 3 fatty acids from fish or plants, and 3) replacing saturated and trans fats with unsaturated fats (especially polyunsaturated). ${ }^{24}$

Since one third of young adults attend college, universities are ideal 
settings for dietary interventions because it is a time of transition, when new lifestyle habits are being formed. ${ }^{8}$ Primary prevention strategies to improve dietary intake at colleges and universities should be planned carefully to target the needs of each student body. College students are an ideal population for intervention because they demonstrate risk of $\mathrm{CHD}$ and are forming new lifestyle habits. ${ }^{8}$

Whole grains and fiber

The Dietary Guidelines for Americans, 2010 recommends consuming at least half of daily grains in their whole form, as evidence shows that consuming whole grains reduce disease risk. ${ }^{80}$ Higher consumption of whole grains was associated with lower risk of CHD in women in the Nurse's Health Study ( $p$ for trend $<0.001$ ). Women in the highest quintile had a $33 \%$ lower relative risk of $\mathrm{CHD}$ compared to the lowest quintile. ${ }^{66}$ Consumption of fiber, especially when in whole grains, is negatively associated with CHD risk in epidemiological studies. ${ }^{25} \mathrm{~A}$ meta-analysis showed that those in the highest quintile of dietary fiber intake have a $29 \%$ lower chance of getting $\mathrm{CHD}$ than those in the lowest quintile of intake. ${ }^{25}$ Randomized controlled trials with soluble fibers show that the average decrease in LDL-C is $10.6 \%, 13 \%, 11.1 \%$ and $8.5 \%$ for guar gum, pectin, barley beta glucan and hydrozypropyl methylcellulose respectively, while maintaining similar TAG and HDL-C concentrations ${ }^{25}$ The most widely used sources of dietary fiber, psyllium and 
oat beta-glucan, show consistent decrease in LDL-C of $5.5 \%$ and $5.3 \%$, respectively, also without affecting TAG and HLD-C. ${ }^{25}$ Brown et al. conducted another meta-analysis of 67 controlled trials on soluble fiber from oat, psyllium and pectin that showed small but significant decreases in TC and HDL-C, without changes in TAG and HDL-C. ${ }^{135}$

Healthy fats: nuts and fatty fish

Unsaturated fats (excluding trans fats), which include MUFA and polyunsaturated fats (PUFA) have positive effects on $\mathrm{CHD}$ risk factors. ${ }^{136}$ For example, replacing saturated fats in the diet with monounsaturated fats (MUFA) and polyunsatured fats (PUFA) has beneficial effects on blood lipids of young adults, including TC and LDL-C. ${ }^{137}$ These unsaturated fats can be found in foods like fatty fish, nuts, olive oil, and avocados.

Eating fish is associated with a lower risk of heart disease in women. ${ }^{63}$ Compared to women who rarely consume fish ( $<1 /$ month), women who consumed more had a $21-34 \%$ lower chance of developing CHD, depending on frequency of intake.$^{63}$ Omega $3 s$, found specifically in fatty fish and fish oil supplements, were also associated with lower risk of $\mathrm{CHD}$, with the highest quintile having a $33 \%$ lower chance of $\mathrm{CHD}$ than those in the highest quintile. $^{63}$

Feeding trials show that increasing intake of fatty fish like salmon leads to reductions in TAG. ${ }^{138,139}$ Gunnarsdottir et al. ${ }^{138}$ showed that intake of 
salmon as part of a eight-week weight loss diet in overweight and obese adults aged 20-40 resulted in the largest decrease in TAG compared to the control, cod and fish oil groups $(p<0.005)$. A longer intervention study of overweight and obese men and women ( 24 weeks) saw reductions in TAG in both the oily fish and rapeseed group and the oily fish and sunflower group compared to the same groups that consumed white fish instead of oily fish $(p=0.05) .{ }^{139}$ Another way to consume healthy fats is by eating nuts, which are considered to be part of a heart healthy diet according to both the American Heart Association and the ATP III ${ }^{28,140}$ and can lead to reductions in TAG ${ }^{141}$ and LDL-C. ${ }^{140}$ Increasing intake of almonds and decreasing intake of trans fatty acids can improve concentrations of HDL-C as well at TAG. ${ }^{48,111,142}$ People who regularly consume nuts have a lower CHD risk compared to those who do not. ${ }^{62,143,144}$ Women in the Nurse's Health Study who consumed nuts at least five times/week had a $35 \%$ reduction in risk for total CHD (non fatal myocardial infarction or fatal $\mathrm{CHD})(\mathrm{RR}=0.65,95 \% \mathrm{Cl}(0.47-0.89), \mathrm{p}$ for trend $=0.0009$ ) compared to women who rarely or never ate nuts. ${ }^{144}$ In the Physician's Health Study, men who consumed nuts more than twice per week had a $47 \%$ reduction in risk of sudden cardiac death $(\mathrm{RR}=0.53, \mathrm{Cl} 0.30$ 0.92). ${ }^{62}$ In the Adventist Health Study, people who consumed nuts more than four times per week had $48 \%$ fewer fatal CHD events (RR=0.52; $95 \%,[\mathrm{Cl}]$ (0.36 to 0.76 ) and $51 \%$ fewer nonfatal myocardial infarctions ( $R R=0.49 ; 95 \%$ 
$\mathrm{Cl}, 0.28$ to 0.85$)$, compared with those who consumed nuts less than once per week. ${ }^{143}$

Another benefit of nuts is that they are an easily consumed source of healthy fats. They can be eaten as snacks, incorporated into many dishes, and do not need to be cooked, and so may be easier to incorporate into many different diets than other high MUFA or PUFA foods like oils. ${ }^{134}$ Incorporating convenient healthy foods like nuts into a heart healthy diet may increase compliance with dietary recommendations. ${ }^{134}$

\section{Decreasing sugar intake}

Many studies show that high intakes of total sugar as part of an unhealthy dietary pattern can increase risk of $\mathrm{CHD} .{ }^{145,}{ }^{146}$ Despite the recent recommendation by the American Heart Association to limit intake of added sugars to no more than $5 \%$ of total kcals, ${ }^{26} 40 \%$ of young adults in college consume more than double this amount. ${ }^{147}$ Added sugar intake was correlated with $\mathrm{CHD}$ risk factors in a nationally representative sample of US adults. ${ }^{148}$ Individuals who consumed less added sugar had lower TAG concentrations ( $p=0.02$ for linear trend), women who consumed less added sugar had lower LDL-C concentrations ( $p=0.047$ for linear trend), and those who consumed more added sugar had lower HDL-C concentrations ( $p=0.01$ for linear trend). ${ }^{148}$ 
Increasing fruit and vegetable consumption

Increasing fruit and vegetable consumption has historically been a high priority in national dietary guidelines and continues to be a major part of dietary recommendations in the US today. ${ }^{80}$ High intakes of fruits and vegetables as part of a healthy dietary pattern can reduce risk of $\mathrm{CHD} \cdot{ }^{149} \mathrm{~A}$ combined analysis of data from the Nurse's Health Study and the Physicians Follow Up Study examined a sample of 84,251 people and showed that a one serving per day increase in fruits and vegetables was associated with a $4 \%$ lower relative risk for $\mathrm{CHD}[\mathrm{Cl} 0.94-0.99, \mathrm{p}=0.01$ for trend $] .{ }^{64}$ Another metaanalysis of nine cohort studies showed that each additional fruit per day decreased $\mathrm{CHD}$ risk ratio by $7 \%$ and each additional vegetables decreased CHD risk ratio by $4 \% .{ }^{65}$

Increasing physical activity

The American College of Sports Medicine's (ACSM) guidelines are geared to promote and maintain health for healthy adults aged 18-65 years. ${ }^{27}$ The guidelines were established utilizing research showing a dose-response relationship between physical activity and a lowered risk of cardiovascular disease. ${ }^{27}$ These guidelines include at least 30 minutes of moderate intensity physical activity five days per week or $\mathbf{2 0}$ minutes of vigorous physical activity three days per week. ${ }^{27}$ Moderate physical activity is defined as something that elevates the heart rate and is equivalent to a brisk walk, and vigorous intensity 
activity is identified by rapid breathing and a more substantial increase in heart rate, and is equivalent to jogging. ${ }^{27}$ Two other recommended elements of good health maintenance are stretching exercises to promote flexibility and performing 8-10 exercises to build strength in the major muscle groups, two or more days per week, with weights allowing for 8-12 repetitions of each exercise. $^{27}$

\section{Diet Education as a means of risk reduction}

Dietary interventions are primary prevention measures that effectively reduce $\mathrm{CHD}$ risk. ${ }^{29,}{ }^{150}$ Improving $\mathrm{CHD}$ through diet is not new; decreasing SFA and increasing PUFA have been recommended as CVD prevention strategies since $1981^{151}$ and a review in 1997 concluded that individual dietary intervention could allow the United Kingdom to achieve $35 \%$ of their $\mathrm{CHD}$ reduction target. ${ }^{150}$ The ATP II nutrition recommendation was composed of Step I and II diets. The Step I and II diets contain progressive reductions in SFA and cholesterol with a Step I diet containing $\leq 30 \%$ of total energy from fat and $\leq 10 \%$ from SFA and $\leq 300 \mathrm{mg}$ cholesterol and the Step II diet with $\leq 7 \%$ of energy from SFA and $\leq 200 \mathrm{mg}$ cholesterol. ${ }^{152} \mathrm{~A}$ meta-analysis of intervention studies in free-living subjects employing these dietary change approaches shows that Step I and II can respectively reduce CHD risk factors, including TC (10\% and 13\%), LDL-C (12\% and 16\%) and TAG (8\% and $8 \%)$ $(p<0.001) .{ }^{152}$ While the results of this analysis showed a greater decrease in 
plasma lipids in Step II than in Step I interventions $(p<0.001)$, it also indicated a decrease of $7 \%(p=0.05)$ in HDL-C in Step II but not Step I interventions. ${ }^{152}$ This show that the further decrease in fat positively impacts LDL-C, TC and TAG, but negatively impacts HDL-C. ${ }^{152}$

The evidence for dietary interventions in young adults

While there is limited research on the impact of nutrition education on lipid concentrations in college students, who are a population of interest due to their worsening health profile, ${ }^{153}$ some research is available on the impact of nutrition education on the diet of college students. ${ }^{46,47,60}$ Taking a general nutrition course increases fruit and vegetable intake and whole grain intake, and decreases soft drink consumption in college students. ${ }^{46,47,60}$ Eighty students with an average age of $20.2 \pm 1.4$ years and BMI of $26.3 \pm 5.6$ took a semester long general nutrition course and participated in pre and post testing. ${ }^{46,47,60}$ Students increased their consumption (cups/day) of vegetables, fresh vegetables, fruit, and fresh fruit, and decreased their consumption of French fries $(p<0.05) .{ }^{46}$ They increased their intake of whole grains from 0.37 oz to $1.16 \mathrm{oz}(\mathrm{p}<0.001)$, without a change in total grain intake,${ }^{60}$ and decreased soft drink consumption $(p<0.05) .{ }^{47}$ These results show that nutrition education can improve intake of healthful foods in college students.

Lipid concentrations can be improved by through nutrition feeding interventions. ${ }^{41}$ In Japan, 157 college females aged 18-24 were randomized 
into three groups and fed either a typical lunch, a soy-rich lunch or a fish-rich lunch for five weeks. ${ }^{41}$ After the intervention, TAG was reduced in both the soy and fish groups $(p<0.01) .^{41}$

Since dietary change can be achieved by nutrition education in college students, ${ }^{46,47,60}$ and changes in diet can result in changes in lipid concentrations, ${ }^{41}$ nutrition education should improve lipid concentrations in this population. 


\section{B. METHODOLOGY}

\section{Study Design}

This is a secondary data analysis of the quasi-experimental Health It Up Intervention, which was a prospective pre-post design, using baseline and post-intervention measures. The intervention took place in a General Nutrition course (NFS 207) at the URI Kingston campus, taught by a professor in the Department of Nutrition and Food Sciences. Subjects were recruited through in-class announcements and Sakai announcements. Students were given extra credit for participation in the study.

\section{Study Population}

As the intervention was offered for extra credit, the only exclusion criteria to participate in the study was history of a prior eating disorder. This was assessed through health history questionnaire at baseline testing and through one online survey question, which asked for date of last menstrual period. The Health It Up Intervention had a total of 91 participants, but seven participants were excluded from data analysis; five were $>24$ year of age, one dropped the course and one had gall bladder surgery during the intervention. The final analysis includes 84 participants, 69 females and 15 males. The average age was $19.26 \pm 1.38$, and average body mass index (BMI) is $23.45 \pm$ $3.6 \mathrm{~kg} / \mathrm{m}^{2}$. Only $8 \%$ of participants were nutrition majors, and $24 \%$ were 
kinesiology/physical education majors, leaving $68 \%$ in other majors. The majority of students lived on campus (64\%).

\section{Study Procedures}

\section{Study Design}

Interested students emailed the study coordinator and were sent an online survey in response. Once they completed the survey, they again emailed the study coordinator and arranged a baseline assessment appointment at which they completed various assessment measures and received feedback. After baseline testing they completed an additional online survey with additional dietary screeners. During five of their general nutrition classes, 20 minutes were devoted to the Health It Up Intervention, taught by the study coordinator, where the intervention classes described how diet and physical activity can impact future risk of heart disease and other health issues. The intervention classes included lessons, activities, and discussion. After the intervention, they completed a final online survey and came in for a post-intervention assessment visit where they repeated the same measurements performed at baseline and again received information about their blood lipid and glucose concentrations and blood pressure, and if desired, were given their anthropometric measurements and percent body fat. All study procedures were approved by the the Institutional Review Board of URI (IRB \# HU0910-051) and all participants signed an informed consent. 


\section{Study Location}

The intervention took place in the Swan Hall Auditorium. Baseline and posttesting took place in Ranger Hall, Room 100C and 301. Data analysis occurred in Ranger Hall, Room 301.

1. Survey: Students in NFS207 interested in the study emailed the study coordinator and received the link to an online survey on SurveyMonkey (surveymonkey.com). If a participant consented, he/she filled out a survey with the following information: basic demographic information, body weight and dietary history, bisphenol A screener (a type of plastic found in many disposable water bottles), Percent of Calories from Fat dietary screener, ${ }^{154}$ National Institutes of Health Eating at America's Tables Study All Day Fruit and Vegetable Screener, ${ }^{31}$ Eating Competence Questionnaire, ${ }^{155}$ Weight Related Behaviors Questionnaire, ${ }^{156}$ Mindfulness Attention Awareness Scale, ${ }^{157}$ International Physical Activity Questionnaire, ${ }^{158}$ the Pittsburgh Sleep

Quality Index, ${ }^{159}$ and two questions about motivational change. All questionnaires, with the exception of the bisphenol A screener, were previously validated.

\section{Testing}

The following measures were done at baseline and post-intervention. 
1. Upon survey completion, participants emailed the study coordinator to arrange a baseline testing appointment.

2. Participants arrived at Ranger Hall, room $100 \mathrm{C}$ after a 12-hour overnight fast in Ranger Hall Room 100C for baseline testing. After study details were explained, participants read and signed a consent form. Participants filled out a 4-item health history questionnaire and wrote down three beliefs related to food, eating or nutrition, which were addressed in the intervention classes in order to personalize the diet education.

3. Height was measured with a Seca 220 stadiometer (Seca Corporation, Hamburg, Germany), weight was measured using a calibrated Seca digital 769 scale (Seca Corporation, Hamburg, Germany), and waist circumference was measured at the top of the iliac crest upon exhalation using a Gulick fiberglass, non-stretchable tape measure with an attached tensometer (Patterson Medical, Mount Joy, PA). ${ }^{32}$ Two measurements were taken, and if not within $0.2 \mathrm{~kg}$ of weight, $0.2 \mathrm{~cm}$ of height or $2 \mathrm{~mm}$ of waist circumference, measurements were retaken until two measurements within these parameters were obtained; the mean of the two values was used for analysis. Body mass index was calculated (weight in kilograms/height in meters ${ }^{2}$ ). Percent body fat was determined using a bioelectrical impedance device (BIA) (Omron HBF$\underline{306}$ Body Fat Analyzer, Omron Health Care Products, Issaquah, WA). 
Participant height and weight (as measured by the research team) was entered into the BIA, and the participant then held the BIA with arms firm and outstretched arms until the machine beeped, signaling that the analysis was complete. The Omron HBF-306 is a validated instruments, shown to give similar results as dual-emission x-ray absorptiometry, a highly precise and valid measurement of body fat in adolescents. ${ }^{33}$

4. Biochemical Measurements: Finger stick blood tests were performed with a Cholestech LDX table-top analyzer (Cholestech, Hayward, CA). Cholestech cassettes were tested for quality assurance upon receiving shipment, and optics checks were performed on each analyzer, each day, before testing began. Cholestech LDX is a valid and reliable tool for obtaining TC, HDL-C, nonHDL-C, TAG, calculated LDL-C, TC:HDL-C ratio, and glucose concentrations. ${ }^{34}$ Study personnel explained the results and gave participants their results and the reference values for TC, HDL-C, LDL-C, TAG, and glucose. Participants were encouraged to follow-up with their primary care physician if any values were not within the reference values.

5. Clinical Measurements: Blood pressure was taken with an automatic blood pressure monitor with arm cuff (Omron HEM-711, Omron Health Care Products, Issaquah, WA) after participants were seated for five minutes. One minute after the first measurement, another measure was taken, and if measurements were not within $2 \mathrm{mmHg}$, measurements were retaken one 
minute apart until two consistent measurements within these parameters were obtained. The mean of the two readings were used for analysis.

6. Physical Fitness Measurement: The Queen's College Step Test, a validated measure of cardiovascular fitness, was performed according to standard protocols. ${ }^{36,37}$ Briefly, participants stepped up and down on a standard height step (Pro Survivor 601X timer, Accusplit, San Jose, CA) for three minutes in time to a digital metronome (Model DM50, Seiko 5-Yard Co, Ltd.), with males and females stepping at 24 and 22 beats per minute, respectively (metronome set to 96 and 88). Study personnel encouraged participants to keep up a steady rhythm and after completing the test; participant pulse was measured on the left wrist for 15 seconds and recorded. After completing the test, the information from the step test was used to calculate estimated maximal oxygen consumption $\left(\mathrm{VO}_{2 \max }\right)$ using the following equations, which were validated in college students ${ }^{38,39}:$ Women: $\mathrm{VO}_{2 \max }=65.1-(0.1847 \mathrm{X}$ $\mathrm{HR})$; Men: $\mathrm{VO}_{2 \max }=88.38-\left(0.157^{*} \mathrm{HR}\right)-\left(0.250^{*}\right.$ weight in $\left.\mathrm{kg}\right)$.

7. After baseline testing, participants were asked to fill out a second online survey containing dietary screeners regarding their intake of whole grains, artificial sweeteners, nuts, and legumes. These screeners were not validated and will only be used for exploratory and descriptive analyses.

\section{Specific Methodology to Test Objectives}


Methodology for Primary Aim: Participants will show improvements in plasma lipids from baseline to post-intervention testing.

Concentrations of TC, HDL-C, non-HDL, TAG and glucose and calculated concentrations of LDL-C ${ }^{160}$ obtained from finger-prick blood testing using a Cholestech LDX will be analyzed.

Methodology for Secondary Aims: Participants will show improvements in BMI, waist circumference, body composition, blood pressure and physical fitness.

Percent body fat obtained using bioelectrical impedance, and values obtained through anthropometric measurements of weight and waist circumference (WC) will be analyzed. The average of the two closest blood pressure measurements using an automatic arm cuff will be examined. The number of heart beats/minute and $\mathrm{VO}_{2 \max }$ calculated from the step test will also be analyzed.

Table 6. Calendar of study events

\begin{tabular}{|l|c|c|c|c|c|c|c|}
\hline Study Activities & $11 / 09$ & $12 / 09$ & $1 / 10$ & $2 / 10$ & $3 / 10$ & $4 / 10$ & 2011 \\
\hline IRB approval & $\mathrm{X}$ & & & & & & \\
\hline Measure development & $\mathrm{X}$ & & $\mathrm{X}$ & & & & \\
\hline Training & $\mathrm{X}$ & & $\mathrm{X}$ & & & & \\
\hline Recruitment & & & $\mathrm{X}$ & & & & \\
\hline Baseline data collection & & & $\mathrm{X}$ & $\mathrm{X}$ & & & \\
\hline Intervention & & & & $\mathrm{X}$ & $\mathrm{X}$ & & \\
\hline $\begin{array}{l}\text { Post-intervention data } \\
\text { collection }\end{array}$ & & & & & & $\mathrm{X}$ & \\
\hline Data analysis & & & & & & & $\mathrm{X}$ \\
\hline
\end{tabular}




\section{Diet and Physical Activity Education}

The intervention occurred during 20 minutes at the end of five NFS207 classes. This class had 181 students registered. During each intervention class, attendance was measured using Response RF Pads (Turning Technologies, Youngstown, $\mathrm{OH})$. At the beginning of each class, all students were asked to click one if they were present, and the clicker software generated an excel spreadsheet of students who clicked in. Seven students did not purchase clickers, and so their attendance data could not be tracked and was therefore left as a missing data point for analysis. The session topics are outlined in Table 2. Each topic was presented using PowerPoint and handouts were distributed in each class to reinforce the presentations. Each day one handout summarized the day's topics and another showed students where the recommended foods could be found on campus. During the first three classes, photo cards with photos of foods were distributed. Two activity that used the cards are as follows; 1 . students were given cards with grain products, and towards the end of the presentation, those who thought they were holding cards with whole grains stood up, so everyone could see visual examples, 2. When healthy fats were covered students were given cards in which the amounts of trans, saturated, monounsaturated and polyunsaturated fatty acids were listed on the back and students were asked to discuss the amounts of fat on the cards with the person next to them. During baseline testing, students were asked to provide a few of their food beliefs, i.e. "I 
believe that eating at night makes you fat." One of the most common beliefs was "it's better to eat a lot of small meals instead of fewer large meals." Using this as an example, study personnel researched this belief and found an ADA position paper that talked about the optimal number of meals to eat in a day to prevent weight gain, which is four to six meals per day. ${ }^{161}$ This information was presented to the class. Other topics covered included whether it was unhealthy to eat late at night, and whether breakfast is actually the most important meal of the day.

The Health It Up Intervention aimed to improve risk factors for CHD through dietary education, specifically targeting TAG and HDL-C, as these two risk factors were shown to be most prevalent in first-year URI students. ${ }^{21}$ Physical activity was only covered in one class and because of school cancelation due to flooding, this class took place only days before postintervention testing began, leaving little time for any beneficial effects to be detected. The intervention was comprised of diet and physical activity education, including experiential activities, partner discussion and food sampling. The educational goals of each intervention class, partner discussion topics, interactive activities and foods sampled in the classes are shown in Table 2. The diet education was based on research showing the health impact of specific foods and nutrients, so increasing intake of the beneficial foods and decreasing consumption of the detrimental foods was encouraged (Table 1). 


\section{Data Processing}

Biochemical, anthropometric, and clinical data collected at baseline and post-testing were entered into Excel by study personnel and checked twice for accuracy. Online survey data were exported into Microsoft Excel, and finally all data were exported from Excel into Statistical Package for the Social Sciences (SPSS Inc, Chicago IL), version 19.0 for all analyses.

\section{Data Analysis}

All participants were assigned a random identification number, which was used in all analyses, so that participant confidentiality could be assured. The list linking names and ID numbers is kept in a locked filing cabinet in a locked lab in Ranger Hall Room 301 of the URI Kingston campus. Data analysis examined whether the Health It Up Intervention, as part of a general nutrition course, improved plasma lipid concentrations in participants and the effect of the intervention on other CHD risk factors.

\section{Sample Size}

Sample size was calculated using one-tailed paired samples $t$-test in G*Power 3.1, and the necessary number of participants was calculated to be 75 participants based on an effect size of 0.29 , similar to the results seen by Yamaoka et al. ${ }^{41}$ 
Analysis

To ensure normality, skewness and kurtosis were examined, and appropriate statistical modifications were applied to non-normally distributed data. Outliers, defined as greater than three standard deviations above or below the mean were removed for baseline weight $(n=2)$, WC $(n=2)$, BMI $(n=1)$, TAG $(n=1)$, TC:HDL ratio $(n=1)$, glucose $(n=1)$ and heart beats per minute (step test) $(n=1)$ and at post intervention for weight $(n=2)$, WC $(n=3)$, BMI $(n=1)$, TAG $(n=2)$, TC:HDL ratio $(n=2)$ and estimated $\mathrm{VO}_{2}$ max $(n=2)$. Log transformations were applied to servings of tomato sauce and fruit from the fruit and vegetable screener, as well as to both baseline and post WC. As the grain, artificial sweetener, and nut and legume surveys collected only frequency of consumption data, non-parametric Wilcoxin-signed ranks tests were used to analyze these variables. Continuous variables were presented as mean \pm standard deviation, categorical variables presented as percentages, and consumption frequency data presented as median and range.

To examine the potential impact of attendance on the variables of interest, mixed between within analysis of variances (ANOVAs) were run controlling for baseline values. Six covariates were tested for high correlations with the depedent variables, including BMI, Weight loss, TC, HDL-C, LDL-C, TC, and SBP. No covariates were used, as they were not correlated with the primary dependent variable, TAG at post intervention. Attendance groups 
were used as the between factors variable. Significance for all tests was set at alpha $=0.05$. Effect sizes using partial eta squared were examined, with a small effect $=0.01$, medium effect $=0.06$, large effect $=0.14{ }^{42}$

\section{RESOURCES REQUIRED}

USDA Hatch Grant RHO 0284 provided funding for the study. Cholestech table-top analyzers, automatic blood pressure cuffs, and anthropometric measurement materials in the Lipid Lab were used for testing.

Dr. Kathleen Melanson from the Department of Nutrition and Food Sciences at URI provided step test blocks, timers, and metronomes used for the Queen's College Step Test. The bioelectrical impedance analyzer was provided by the Kinesiology Department, URI. Funding for the food sampling and educational materials was provided by a URI graduate school mini grant. Statistical analysis will be run on computer \#1 in Ranger Hall Room 301. The data being used for analysis are stored on this computer, and the SPSS survival manual, third edition, will be used as a statistical reference. ${ }^{162}$ Elizabeth Dimond, PhD, whose services will be funded by Dr. Ingrid Lofgren of the Department of Food and Nutrition Sciences, will supply statistical guidance. 


\section{BIBLIOGRAPHY}

1. Roger VL, Go AS, Lloyd-Jones DM, et al. Heart disease and stroke statistics--2011 update: a report from the American Heart Association. Circulation. Feb 1 2011;123(4):e18-e209.

2. Health, United States, 2010: With Special Feature on Death and Dying. In: Statistics NCfH, ed. Hyattsville, MD2011.

3. Diabetes Across the United States. (a service of the National Institute of Diabetes and Digestive and Kidney Diseases, National Institutes of Health). Available at: http://www.diabetes.niddk.nih.gov/ populations/index.htm. Accessed Accessed August 24, 2011.

4. Pistrosch F, Natali $\mathrm{A}$, Hanefeld $\mathrm{M}$. Is hyperglycemia a cardiovascular risk factor? Diabetes Care. May 2011;34 Suppl 2:S128-131.

5. Fox CS, Pencina MJ, Meigs JB, Vasan RS, Levitzky YS, D'Agostino $\mathrm{RB}, \mathrm{Sr}$. Trends in the incidence of type 2 diabetes mellitus from the 1970s to the 1990s: the Framingham Heart Study. Circulation. Jun 27 2006;113(25):2914-2918.

6. Retelny VS, Neuendorf A, Roth JL. Nutrition protocols for the prevention of cardiovascular disease. Nutrition in Clinical Practice. Oct-Nov 2008;23(5):468-476.

7. Executive Summary of The Third Report of The National Cholesterol Education Program (NCEP) Expert Panel on Detection, Evaluation, And Treatment of High Blood Cholesterol In Adults (Adult Treatment Panel III). JAMA. May 16 2001;285(19):2486-2497.

8. Huang TT, Harris KJ, Lee RE, Nazir N, Born W, Kaur H. Assessing overweight, obesity, diet, and physical activity in college students. J Am Coll Health. Sep-Oct 2003;52(2):83-86. 
9. McMahan CA, Gidding SS, McGill Jr HC. Coronary heart disease risk factors and atherosclerosis in young people. Journal of Clinical Lipidology. 2008;2(3):118-126.

10. Allan JL, Johnston M, Campbell N. Why do people fail to turn good intentions into action? The role of executive control processes in the translation of healthy eating intentions into action in young Scottish adults. BMC Public Health. 2008;8:123.

11. Gores SE. Addressing nutritional issues in the college-aged client: strategies for the nurse practitioner. J Am Acad Nurse Pract. Jan 2008;20(1):5-10.

12. Wechsler $H$, Lee JE, Kuo M, Seibring M, Nelson TF, Lee H. Trends in college binge drinking during a period of increased prevention efforts. Findings from 4 Harvard School of Public Health College Alcohol Study surveys: 1993-2001. J Am Coll Health. Mar 2002;50(5):203-217.

13. Mihalopoulos NL, Auinger P, Klein JD. The Freshman 15: is it real? $J$ Am Coll Health. Mar-Apr 2008;56(5):531-533.

14. Gordon-Larsen P, Adair LS, Nelson MC, Popkin BM. Five-year obesity incidence in the transition period between adolescence and adulthood: the National Longitudinal Study of Adolescent Health. Am J Clin Nutr. Sep 2004;80(3):569-575.

15. Norman JE, Bild D, Lewis CE, Liu K, West DS. The impact of weight change on cardiovascular disease risk factors in young black and white adults: the CARDIA study. Int J Obes Relat Metab Disord. Mar 2003;27(3):369-376 .

16. Colditz GA, Willett WC, Rotnitzky A, Manson JE. Weight gain as a risk factor for clinical diabetes mellitus in women. Ann Intern Med. Apr 1 1995;122(7):481-486.

17. Kopelman P. Health risks associated with overweight and obesity. Obes Rev. Mar 2007;8 Suppl 1:13-17. 
18. Kozak AT, Daviglus ML, Chan C, Kiefe Cl, Jacobs DR, Jr., Liu K. Relationship of body mass index in young adulthood and health-related quality of life two decades later: the Coronary Artery Risk Development in Young Adults study. Int J Obes (Lond). Jun 152010.

19. Huang TT, Kempf AM, Strother ML, et al. Overweight and components of the metabolic syndrome in college students. Diabetes Care. Dec 2004;27(12):3000-3001.

20. Burke JD, Reilly RA, Morrell JS, Lofgren IE. The University of New Hampshire's Young Adult Health Risk Screening Initiative. J Am Diet Assoc. Oct 2009;109(10):1751-1758.

21. Fernandes J, Lofgren IE. Prevalence of metabolic syndrome and individual criteria in college students. J Am Coll Health. Jan 2011;59(4):313-321 .

22. Lloyd-Jones DM, Wilson PW, Larson MG, et al. Lifetime risk of coronary heart disease by cholesterol levels at selected ages. Arch Intern Med. Sep 8 2003;163(16):1966-1972.

23. Tai ES, Goh SY, Lee JJ, et al. Lowering the criterion for impaired fasting glucose: impact on disease prevalence and associated risk of diabetes and ischemic heart disease. Diabetes Care. Jul 2004;27(7):1728-1734.

24. Hu FB, Willett WC. Optimal diets for prevention of coronary heart disease. JAMA. Nov 27 2002;288(20):2569-2578.

25. Anderson JW, Baird $\mathrm{P}$, Davis $\mathrm{RH}$, Jr., et al. Health benefits of dietary fiber. Nutr Rev. Apr 2009;67(4):188-205.

26. Johnson RK, Appel LJ, Brands M, et al. Dietary sugars intake and cardiovascular health: a scientific statement from the American Heart Association. Circulation. Sep 15 2009;120(11):1011-1020.

27. Haskell W, Lee, I-Min, Pate, Russell. Physical Activity and Public Health: Updated Recommendation for Adults from the American 
College of Sports Medicine and the American Heart Association. Medicine and Science in Sports and Exercise. 2007:1423-1443.

28. Lichtenstein $A H$, Appel LJ, Brands $M$, et al. Diet and lifestyle recommendations revision 2006: a scientific statement from the American Heart Association Nutrition Committee. Circulation. Jul 4 2006;114(1):82-96.

29. Leon AS, Sanchez OA. Response of blood lipids to exercise training alone or combined with dietary intervention. Med Sci Sports Exerc. Jun 2001;33(6 Suppl):S502-515; discussion S528-509.

30. Cheng C, Graziani C, Diamond JJ. Cholesterol-lowering effect of the Food for Heart Nutrition Education Program. J Am Diet Assoc. Dec 2004;104(12):1868-1872.

31. Thompson FE, Subar AF, Smith AF, et al. Fruit and vegetable assessment: performance of 2 new short instruments and a food frequency questionnaire. J Am Diet Assoc. Dec 2002;102(12):17641772.

32. Joint National Committee on Prevention D, Evaluation, and Treatment of High Blood Pressure. The Practical Guide: Identification, Evaluation, and Treatment of Overweight and Obesity in Adults. In: National Institute of Health; National Heart L, and Blood Institute ed. Bethesda, MD: North American Association for the Study of Obesity; 2000.

33. Lintsi M, Kaarma H, Kull I. Comparison of hand-to-hand bioimpedance and anthropometry equations versus dual-energy X-ray absorptiometry for the assessment of body fat percentage in 17-18-year-old conscripts. Clin Physiol Funct Imaging. Mar 2004;24(2):85-90.

34. Santee J. Accuracy and precision of the Cholestech LDX System in monitoring blood lipid levels. Am J Health Syst Pharm. Sep 15 2002;59(18):1774-1779.

35. Morrell JS, Lofgren IE, Burke JD, Reilly RA. Metabolic syndrome, obesity, and related risk factors among college men and women. $J$ Am Coll Health. 2012;60(1):82-89. 
36. Chatterjee S, Chatterjee P, Bandyopadhyay A. Validity of Queen's College Step Test for estimation of maximum oxygen uptake in female students. Indian J Med Res. Jan 2005;121(1):32-35.

37. Chatterjee S, Chatterjee P, Mukherjee PS, Bandyopadhyay A. Validity of Queen's College step test for use with young Indian men. Br J Sports Med. Jun 2004;38(3):289-291.

38. McArdle WD, Katch FI, Pechar GS, Jacobson L, Ruck S. Reliability and interrelationships between maximal oxygen intake, physical work capacity and step-test scores in college women. Med Sci Sports. Winter 1972;4(4):182-186.

39. Blissmer B, Meebe, S, Riebe D, Greene, GW. An accurate and reliable field test for estimating health promotion effects on fitness: Predicting cardiorespiratory fitness in men using a simple three minute assessment. Paper presented at: 137th American Public Health Association Annual Meeting2009; Philadelphia, PA.

40. Myers EF. ADA Evidence Analysis Library. J Am Diet Assoc. May 2005;105(5 Suppl 1):S79.

41. Yamaoka S, Fujimoto M, Mori M, Mori H, Yamori Y. Risk reduction of lifestyle-related diseases in young adults on soy- or fish-rich traditional japanese meals. Clinical and Experimental Pharmacology and Physiology. 2007;34(November):S79-S81.

42. Cohen J. Statistical power analysis for the behavioral sciences 2nd ed. New Jersey: Lawrence Erlbaum; 1988.

43. Racette SB, Deusinger SS, Strube MJ, Highstein GR, Deusinger RH. Changes in weight and health behaviors from freshman through senior year of college. Journal of Nutrition Education and Behavior. Jan-Feb 2008;40(1):39-42.

44. Krauss RM, Winston M, Fletcher BJ, Grundy SM. Obesity : impact on cardiovascular disease. Circulation. Oct 6 1998;98(14):1472-1476. 
45. Ha EJ, Caine-Bish N. Interactive introductory nutrition course focusing on disease prevention increased whole-grain consumption by college students. Journal of Nutrition Education and Behavior. Jul-Aug 2011;43(4):263-267.

46. Ha EJ, Caine-Bish N. Effect of nutrition intervention using a general nutrition course for promoting fruit and vegetable consumption among college students. Journal of Nutrition Education and Behavior. Mar-Apr 2009;41(2):103-109.

47. Ha EJ, Caine-Bish N, Holloman C, Lowry-Gordon K. Evaluation of effectiveness of class-based nutrition intervention on changes in soft drink and milk consumption among young adults. Nutr J. 2009;8:50.

48. Kodama S, Tanaka S, Saito K, et al. Effect of aerobic exercise training on serum levels of high-density lipoprotein cholesterol: a meta-analysis. Arch Intern Med. May 28 2007;167(10):999-1008.

49. Fan AZ, Russell M, Naimi T, et al. Patterns of alcohol consumption and the metabolic syndrome. J Clin Endocrinol Metab. Oct 2008;93(10):3833-3838.

50. Lloyd-Richardson EE, Bailey S, Fava JL, Wing R. A prospective study of weight gain during the college freshman and sophomore years. Prev Med. Mar 2009;48(3):256-261.

51. Tirosh A, Shai I, Tekes-Manova D, et al. Normal fasting plasma glucose levels and type 2 diabetes in young men. $N$ Engl J Med. Oct 6 2005;353(14):1454-1462.

52. Obarzanek E, Sacks FM, Vollmer WM, et al. Effects on blood lipids of a blood pressure-lowering diet: the Dietary Approaches to Stop Hypertension (DASH) Trial. Am J Clin Nutr. Jul 2001;74(1):80-89.

53. Miller ER, 3rd, Erlinger TP, Young DR, et al. Results of the Diet, Exercise, and Weight Loss Intervention Trial (DEW-IT). Hypertension. Nov 2002;40(5):612-618. 
54. Jenkins DJ, Kendall CW, Marchie A, et al. Type 2 diabetes and the vegetarian diet. Am J Clin Nutr. Sep 2003;78(3 Suppl):610S-616S.

55. Ribeiro Al, Lopes C, Barros H, de Pina MD. After a quarter of century, reduction in Coronary Heart Disease Mortality bypassed young adult males in Portugal. Int J Cardiol. Sep 82011.

56. O'Flaherty M, Ford E, Allender S, Scarborough P, Capewell S. Coronary heart disease trends in England and Wales from 1984 to 2004: concealed levelling of mortality rates among young adults. Heart. Feb 2008;94(2):178-181.

57. Magnussen $\mathrm{CG}$, Niinikoski $\mathrm{H}$, Juonala $\mathrm{M}$, et al. When and how to start prevention of atherosclerosis? Lessons from the Cardiovascular Risk in the Young Finns Study and the Special Turku Coronary Risk Factor Intervention Project. Pediatr Nephrol. Aug 302011.

58. Mokdad AH, Marks JS, Stroup DF, Gerberding JL. Actual causes of death in the United States, 2000. JAMA. Mar 10 2004;291(10):12381245.

59. Larson NI, Neumark-Sztainer DR, Harnack LJ, Wall MM, Story MT, Eisenberg ME. Fruit and vegetable intake correlates during the transition to young adulthood. Am J Prev Med. Jul 2008;35(1):33-37.

60. Adeyo O, Horn PJ, Lee S, et al. The yeast lipin orthologue Pah1p is important for biogenesis of lipid droplets. J Cell Biol. Mar 21 2011;192(6):1043-1055.

61. Rodney G. Bowden PD. Lipid Levels in a Cohort of Sedentary University Students. The Internet Journal of Cardiovascular Research. $2005 ; 2(2)$.

62. Albert CM, Gaziano JM, Willett WC, Manson JE. Nut consumption and decreased risk of sudden cardiac death in the Physicians' Health Study. Arch Intern Med. Jun 24 2002;162(12):1382-1387. 
63. Hu FB, Bronner L, Willett WC, et al. Fish and omega-3 fatty acid intake and risk of coronary heart disease in women. JAMA. Apr 10 2002;287(14):1815-1821.

64. Joshipura KJ, Hu FB, Manson JE, et al. The effect of fruit and vegetable intake on risk for coronary heart disease. Ann Intern Med. Jun 19 2001;134(12):1106-1114.

65. Dauchet L, Amouyel P, Hercberg S, Dallongeville J. Fruit and vegetable consumption and risk of coronary heart disease: a meta-analysis of cohort studies. Journal of Nutrition. Oct 2006;136(10):2588-2593.

66. Liu S, Stampfer MJ, Hu FB, et al. Whole-grain consumption and risk of coronary heart disease: results from the Nurses' Health Study. Am J Clin Nutr. Sep 1999;70(3):412-419.

67. McMahan CA, Gidding SS, Fayad ZA, et al. Risk scores predict atherosclerotic lesions in young people. Arch Intern Med. Apr 25 2005;165(8):883-890.

68. Lloyd-Jones D, Adams RJ, Brown TM, et al. Heart disease and stroke statistics--2010 update: a report from the American Heart Association. Circulation. Feb 23 2010;121(7):e46-e215.

69. Briefel RR, Johnson CL. Secular trends in dietary intake in the United States. Annu Rev Nutr. 2004;24:401-431.

70. Prevalence of physical activity, including lifestyle activities among adults--United States, 2000-2001. MMWR Morb Mortal Wkly Rep. Aug 15 2003;52(32):764-769.

71. Danaei G, Ding EL, Mozaffarian D, et al. The preventable causes of death in the United States: comparative risk assessment of dietary, lifestyle, and metabolic risk factors. PLoS Med. Apr 28 2009;6(4):e1000058. 
72. Ford ES, Ajani UA, Croft JB, et al. Explaining the decrease in U.S. deaths from coronary disease, 1980-2000. N Engl J Med. Jun 7 2007;356(23):2388-2398.

73. Quandt SA, Bell RA, Snively BM, Vitolins MZ, Wetmore-Arkader LK, Arcury TA. Dietary Fat Reduction Behaviors among African American, American Indian, and White Older Adults with Diabetes. J Nutr Elder. Apr 1 2009;28(2):143-157.

74. Rigotti NA, Thomas GS, Leaf A. Exercise and coronary heart disease. Annu Rev Med. 1983;34:391-412.

75. Taylor HL, Buskirk ER, Remington RD. Exercise in controlled trials of the prevention of coronary heart disease. Fed Proc. May 1973;32(5):1623-1627.

76. Pletcher MJ, Lazar L, Bibbins-Domingo K, et al. Comparing impact and cost-effectiveness of primary prevention strategies for lipid-lowering. Ann Intern Med. Feb 17 2009;150(4):243-254.

77. Sinzinger $\mathrm{H}$, Wolfram R, Peskar BA. Muscular side effects of statins. $J$ Cardiovasc Pharmacol. Aug 2002;40(2):163-171.

78. Hlatky MA, Rogers WJ, Johnstone I, et al. Medical care costs and quality of life after randomization to coronary angioplasty or coronary bypass surgery. Bypass Angioplasty Revascularization Investigation (BARI) Investigators. N Engl J Med. Jan 9 1997;336(2):92-99.

79. Grundy SM, Balady GJ, Criqui MH, et al. Primary prevention of coronary heart disease: guidance from Framingham: a statement for healthcare professionals from the AHA Task Force on Risk Reduction. American Heart Association. Circulation. May 12 1998;97(18):18761887.

80. Dietary Guidelines for Americans, 2010. In: Services USDoAaUSDoHaH, ed. 7th Edition ed. Washington, DC: U.S. Government Printing Office; 2010. 
81. Overweight, obesity, and health risk. National Task Force on the Prevention and Treatment of Obesity. Arch Intern Med. Apr 10 2000;160(7):898-904.

82. Lavie CJ, Milani RV, Ventura HO. Obesity and cardiovascular disease: risk factor, paradox, and impact of weight loss. J Am Coll Cardiol. May 26 2009;53(21):1925-1932.

83. Caspersen CJ, Pereira MA, Curran KM. Changes in physical activity patterns in the United States, by sex and cross-sectional age. Med Sci Sports Exerc. Sep 2000;32(9):1601-1609.

84. Nelson MC, Neumark-Stzainer D, Hannan PJ, Sirard JR, Story M. Longitudinal and secular trends in physical activity and sedentary behavior during adolescence. Pediatrics. Dec 2006;118(6):e1627-1634.

85. Desai MN, Miller WC, Staples B, Bravender T. Risk factors associated with overweight and obesity in college students. J Am Coll Health. JulAug 2008;57(1):109-114.

86. Lowry R, Galuska DA, Fulton JE, Wechsler H, Kann L, Collins JL. Physical activity, food choice, and weight management goals and practices among US college students. Am J Prev Med. Jan 2000;18(1):18-27.

87. Demory-Luce D, Morales M, Nicklas T, Baranowski T, Zakeri I, Berenson $\mathrm{G}$. Changes in food group consumption patterns from childhood to young adulthood: the Bogalusa Heart Study. J Am Diet Assoc. Nov 2004;104(11):1684-1691.

88. McNaughton SA, Dunstan DW, Ball K, Shaw J, Crawford D. Dietary quality is associated with diabetes and cardio-metabolic risk factors. Journal of Nutrition. Apr 2009;139(4):734-742.

89. McMahan CA, Gidding SS, Viikari JS, et al. Association of Pathobiologic Determinants of Atherosclerosis in Youth risk score and 15-year change in risk score with carotid artery intima-media thickness in young adults (from the Cardiovascular Risk in Young Finns Study). Am J Cardiol. Oct 1 2007;100(7):1124-1129. 
90. Stipanuk MH, ed Biochemical, Physiological, \& Molecular Aspects of Human Nutrition. 2 ed. Ithaca, NY: Saunders, an imprint of Elsevier, Inc.; 2006. Gary M. Whitford P, DMD, ed. Fluoride.

91. Gropper SS, Smith, Jack, L., Groff, James L. Advanced Nutrition and Human Metabolism. 5th ed. Belmont, CA: Wadsworth Cengage Learning; 2009.

92. Wang DQ. Regulation of intestinal cholesterol absorption. Annu Rev Physiol. 2007;69:221-248.

93. Rolfes S, Whitney, E. Understanding Normal and Clinical Nutrition. 7 ed. Belmont, CA: Thompson Learning, Inc; 2006.

94. Kwiterovich PO, Jr. The metabolic pathways of high-density lipoprotein, low-density lipoprotein, and triglycerides: a current review. $\mathrm{Am} J$ Cardiol. Dec 21 2000;86(12A):5L-10L.

95. Cooper AD. Hepatic uptake of chylomicron remnants. J Lipid Res. Nov 1997;38(11):2173-2192.

96. Brown MS, Kovanen PT, Goldstein JL. Regulation of plasma cholesterol by lipoprotein receptors. Science. May 8 1981;212(4495):628-635.

97. Cullen P. Evidence that triglycerides are an independent coronary heart disease risk factor. Am J Cardiol. Nov 1 2000;86(9):943-949.

98. Sarwar N, Danesh J, Eiriksdottir G, et al. Triglycerides and the risk of coronary heart disease: 10,158 incident cases among 262,525 participants in 29 Western prospective studies. Circulation. Jan 30 2007;115(4):450-458.

99. Sarwar N, Sandhu MS, Ricketts SL, et al. Triglyceride-mediated pathways and coronary disease: collaborative analysis of 101 studies. Lancet. May 8 2010;375(9726):1634-1639. 
100. Kris-Etherton PM, Pearson TA, Wan Y, et al. High-monounsaturated fatty acid diets lower both plasma cholesterol and triacylglycerol concentrations. Am J Clin Nutr. Dec 1999;70(6):1009-1015.

101. Smith JB, Niven BE, Mann JI. The effect of reduced extrinsic sucrose intake on plasma triglyceride levels. European Journal of Clinical Nutrition. Aug 1996;50(8):498-504.

102. Jelski W, Szmitkowski M. [Effect of ethanol on metabolic syndrome]. Pol Arch Med Wewn. Jul 2007;117(7):306-311.

103. Grucza RA, Norberg KE, Bierut LJ. Binge drinking among youths and young adults in the United States: 1979-2006. J Am Acad Child Adolesc Psychiatry. Jul 2009;48(7):692-702.

104. Parks EJ, Skokan LE, Timlin MT, Dingfelder CS. Dietary sugars stimulate fatty acid synthesis in adults. Journal of Nutrition. Jun 2008;138(6):1039-1046.

105. West DS, Bursac Z, Quimby D, et al. Self-reported sugar-sweetened beverage intake among college students. Obesity (Silver Spring). Oct 2006;14(10):1825-1831.

106. Barter PJ, Nicholls S, Rye KA, Anantharamaiah GM, Navab M, Fogelman AM. Antiinflammatory properties of HDL. Circ Res. Oct 15 2004;95(8):764-772.

107. Barn K, Laftavi M, Pierce D, Ying C, Boden WE, Pankewycz O. Low levels of high-density lipoprotein cholesterol: an independent risk factor for late adverse cardiovascular events in renal transplant recipients. Transpl Int. Jun 2010;23(6):574-579.

108. Volek JS, Fernandez ML, Feinman RD, Phinney SD. Dietary carbohydrate restriction induces a unique metabolic state positively affecting atherogenic dyslipidemia, fatty acid partitioning, and metabolic syndrome. Prog Lipid Res. Sep 2008;47(5):307-318. 
109. Meigs JB, Nathan DM, Wilson PW, Cupples LA, Singer DE. Metabolic risk factors worsen continuously across the spectrum of nondiabetic glucose tolerance. The Framingham Offspring Study. Ann Intern Med. Apr 1 1998;128(7):524-533.

110. Boden WE. High-density lipoprotein cholesterol as an independent risk factor in cardiovascular disease: assessing the data from Framingham to the Veterans Affairs High--Density Lipoprotein Intervention Trial. Am J Cardiol. Dec 21 2000;86(12A):19L-22L.

111. Qian J. Reduction of risk factors for cardiovascular diseases in African Americans

with a 12-week nutrition education program. Nutrition Research. 3/16/2007 2007;27:252-257.

112. Wilson PW, D'Agostino RB, Levy D, Belanger AM, Silbershatz $H$, Kannel WB. Prediction of coronary heart disease using risk factor categories. Circulation. May 12 1998;97(18):1837-1847.

113. Stampfer MJ, Sacks FM, Salvini S, Willett WC, Hennekens CH. A prospective study of cholesterol, apolipoproteins, and the risk of myocardial infarction. N Engl J Med. Aug 8 1991;325(6):373-381.

114. Law MR, Wald NJ, Thompson SG. By how much and how quickly does reduction in serum cholesterol concentration lower risk of ischaemic heart disease? BMJ. Feb 5 1994;308(6925):367-372.

115. Cheng AY, Leiter LA. Implications of recent clinical trials for the National Cholesterol Education Program Adult Treatment Panel III guidelines. Curr Opin Cardiol. Jul 2006;21(4):400-404.

116. Grundy SM, Cleeman JI, Merz CN, et al. Implications of recent clinical trials for the National Cholesterol Education Program Adult Treatment Panel III guidelines. Arterioscler Thromb Vasc Biol. Aug 2004;24(8):e149-161.

117. Baigent C, Keech A, Kearney PM, et al. Efficacy and safety of cholesterol-lowering treatment: prospective meta-analysis of data from 
90,056 participants in 14 randomised trials of statins. Lancet. Oct 8 2005;366(9493):1267-1278.

118. LaRosa JC, He J, Vupputuri S. Effect of statins on risk of coronary disease: a meta-analysis of randomized controlled trials. JAMA. Dec 22-29 1999;282(24):2340-2346.

119. Jansen S, Lopez-Miranda J, Castro P, et al. Low-fat and highmonounsaturated fatty acid diets decrease plasma cholesterol ester transfer protein concentrations in young, healthy, normolipemic men. Am J Clin Nutr. Jul 2000;72(1):36-41.

120. Fusegawa Y, Kelley KL, Sawyer JK, Shah RN, Rudel LL. Influence of dietary fatty acid composition on the relationship between CETP activity and plasma lipoproteins in monkeys. J Lipid Res. Nov 2001;42(11):1849-1857.

121. Ikewaki K, Nishiwaki M, Sakamoto $T$, et al. Increased catabolic rate of low density lipoproteins in humans with cholesteryl ester transfer protein deficiency. J Clin Invest. Sep 1995;96(3):1573-1581.

122. Brownlee M. Biochemistry and molecular cell biology of diabetic complications. Nature. Dec 13 2001;414(6865):813-820.

123. Genuth $S$, Alberti KG, Bennett $P$, et al. Follow-up report on the diagnosis of diabetes mellitus. Diabetes Care. Nov 2003;26(11):31603167.

124. Rijkelijkhuizen JM, Nijpels G, Heine RJ, Bouter LM, Stehouwer CD, Dekker JM. High risk of cardiovascular mortality in individuals with impaired fasting glucose is explained by conversion to diabetes: the Hoorn study. Diabetes Care. Feb 2007;30(2):332-336.

125. Blake DR, Meigs JB, Muller DC, Najjar SS, Andres R, Nathan DM. Impaired glucose tolerance, but not impaired fasting glucose, is associated with increased levels of coronary heart disease risk factors: results from the Baltimore Longitudinal Study on Aging. Diabetes. Aug 2004;53(8):2095-2100. 
126. Gabir MM, Hanson RL, Dabelea D, et al. The 1997 American Diabetes Association and 1999 World Health Organization criteria for hyperglycemia in the diagnosis and prediction of diabetes. Diabetes Care. Aug 2000;23(8):1108-1112.

127. Hu FB, Stampfer MJ, Solomon CG, et al. The impact of diabetes mellitus on mortality from all causes and coronary heart disease in women: 20 years of follow-up. Arch Intern Med. Jul 23 2001;161(14):1717-1723.

128. Lotufo PA, Gaziano JM, Chae CU, et al. Diabetes and all-cause and coronary heart disease mortality among US male physicians. Arch Intern Med. Jan 22 2001;161(2):242-247.

129. Houstis N, Rosen ED, Lander ES. Reactive oxygen species have a causal role in multiple forms of insulin resistance. Nature. Apr 13 2006;440(7086):944-948.

130. Due A, Larsen TM, Hermansen $\mathrm{K}$, et al. Comparison of the effects on insulin resistance and glucose tolerance of 6-mo highmonounsaturated-fat, low-fat, and control diets. Am J Clin Nutr. Apr 2008;87(4):855-862.

131. Wing RR, Venditti E, Jakicic JM, Polley BA, Lang W. Lifestyle intervention in overweight individuals with a family history of diabetes. Diabetes Care. Mar 1998;21(3):350-359.

132. Singhal N, Misra A, Shah P, Gulati S. Effects of controlled school-based multi-component model of nutrition and lifestyle interventions on behavior modification, anthropometry and metabolic risk profile of urban Asian Indian adolescents in North India. European Journal of Clinical Nutrition. Apr 2010;64(4):364-373.

133. Bachmann J, Friess $\mathrm{H}$, Martignoni ME. [Molecular mechanisms and its clinical impact in cancer cachexia]. $Z$ Gastroenterol. Dec 2008;46(12):1384-1392.

134. Rajaram S, Burke K, Connell B, Myint T, Sabate J. A monounsaturated fatty acid-rich pecan-enriched diet favorably alters the serum lipid 
profile of healthy men and women. Journal of Nutrition. Sep 2001;131(9):2275-2279.

135. Brown L, Rosner B, Willett WW, Sacks FM. Cholesterol-lowering effects of dietary fiber: a meta-analysis. Am J Clin Nutr. Jan 1999;69(1):30-42.

136. Kris-Etherton $\mathrm{P}$, Daniels $\mathrm{SR}$, Eckel $\mathrm{RH}$, et al. AHA scientific statement: summary of the Scientific Conference on Dietary Fatty Acids and Cardiovascular Health. Conference summary from the Nutrition Committee of the American Heart Association. Journal of Nutrition. Apr 2001;131(4):1322-1326.

137. Hodson L, Skeaff CM, Chisholm WA. The effect of replacing dietary saturated fat with polyunsaturated or monounsaturated fat on plasma lipids in free-living young adults. European Journal of Clinical Nutrition. Oct $2001 ; 55(10): 908-915$.

138. Gunnarsdottir I, Tomasson $\mathrm{H}$, Kiely M, et al. Inclusion of fish or fish oil in weight-loss diets for young adults: effects on blood lipids. Int $J$ Obes (Lond). Jul 2008;32(7):1105-1112.

139. Moore CS, Bryant SP, Mishra GD, et al. Oily fish reduces plasma triacylglycerols: a primary prevention study in overweight men and women. Nutrition. Oct 2006;22(10):1012-1024.

140. Prevalence of overweight and obesity among adults with diagnosed diabetes--United States, 1988-1994 and 1999-2002. MMWR Morb Mortal Wkly Rep. Nov 19 2004;53(45):1066-1068.

141. Alper CM, Mattes RD. Peanut consumption improves indices of cardiovascular disease risk in healthy adults. J Am Coll Nutr. Apr 2003;22(2):133-141.

142. Mukuddem-Petersen J, Oosthuizen $\mathrm{W}$, Jerling JC. A systematic review of the effects of nuts on blood lipid profiles in humans. Journal of Nutrition. Sep 2005;135(9):2082-2089. 
143. Fraser GE, Sabate J, Beeson WL, Strahan TM. A possible protective effect of nut consumption on risk of coronary heart disease. The Adventist Health Study. Arch Intern Med. Jul 1992;152(7):1416-1424.

144. Hu FB, Stampfer MJ, Manson JE, et al. Frequent nut consumption and risk of coronary heart disease in women: prospective cohort study. BMJ. Nov 14 1998;317(7169):1341-1345.

145. Berg CM, Lappas G, Strandhagen E, et al. Food patterns and cardiovascular disease risk factors: the Swedish INTERGENE research program. Am J Clin Nutr. Aug 2008;88(2):289-297.

146. McNaughton SA, Mishra GD, Brunner EJ. Food patterns associated with blood lipids are predictive of coronary heart disease: the Whitehall II study. Br J Nutr. Aug 2009;102(4):619-624.

147. Song WOPD, R.D, Schuette, Lisa K. Capt. M.S., R.D, Huang, Ya-Li M.S., Hoerr, Sharon Ph.D, R.D. Food Group Intake Patterns in Relation to Nutritional Adequacy of Young Adults. Nutrition Research. 1996;16(9):1507-1519.

148. Welsh JA, Sharma A, Abramson JL, Vaccarino V, Gillespie C, Vos MB. Caloric sweetener consumption and dyslipidemia among US adults. JAMA. Apr 21 2010;303(15):1490-1497.

149. Hoffmann K, Zyriax BC, Boeing H, Windler E. A dietary pattern derived to explain biomarker variation is strongly associated with the risk of coronary artery disease. Am J Clin Nutr. Sep 2004;80(3):633-640.

150. Brunner E, White I, Thorogood M, Bristow A, Curle D, Marmot M. Can dietary interventions change diet and cardiovascular risk factors? A meta-analysis of randomized controlled trials. Am J Public Health. Sep 1997;87(9):1415-1422.

151. Rose G. Strategy of prevention: lessons from cardiovascular disease. Br Med J (Clin Res Ed). Jun 6 1981;282(6279):1847-1851. 
152. Yu-Poth $S$, Zhao G, Etherton $T$, Naglak M, Jonnalagadda S, KrisEtherton PM. Effects of the National Cholesterol Education Program's Step I and Step II dietary intervention programs on cardiovascular disease risk factors: a meta-analysis. Am J Clin Nutr. Apr 1999;69(4):632-646.

153. Winkleby MA, Cubbin $C$. Changing patterns in health behaviors and risk factors related to chronic diseases, 1990-2000. Am J Health Promot. Sep-Oct 2004;19(1):19-27.

154. Thompson FE, Midthune D, Subar AF, Kipnis V, Kahle LL, Schatzkin A. Development and evaluation of a short instrument to estimate usual dietary intake of percentage energy from fat. $J$ Am Diet Assoc. May 2007;107(5):760-767.

155. Lohse B, Satter E, Horacek T, Gebreselassie T, Oakland MJ. Measuring eating competence: psychometric properties and validity of the ecSatter Inventory. Journal of Nutrition Education and Behavior. Sep-Oct 2007;39(5 Suppl):S154-166.

156. Schembre S, Greene G, Melanson K. Development and validation of a weight-related eating questionnaire. Eat Behav. Apr 2009;10(2):119124.

157. Brown KW, Ryan RM. The benefits of being present: mindfulness and its role in psychological well-being. J Pers Soc Psychol. Apr 2003;84(4):822-848.

158. Papathanasiou G, Georgoudis G, Georgakopoulos D, Katsouras C, Kalfakakou V, Evangelou A. Criterion-related validity of the short International Physical Activity Questionnaire against exercise capacity in young adults. Eur J Cardiovasc Prev Rehabil. Aug 2010;17(4):380386.

159. Buysse DJ, Reynolds CF, 3rd, Monk TH, Berman SR, Kupfer DJ. The Pittsburgh Sleep Quality Index: a new instrument for psychiatric practice and research. Psychiatry Res. May 1989;28(2):193-213. 
160. Friedewald WT, Levy RI, Fredrickson DS. Estimation of the concentration of low-density lipoprotein cholesterol in plasma, without use of the preparative ultracentrifuge. Clin Chem. Jun 1972;18(6):499502.

161. Seagle HM, Strain GW, Makris A, Reeves RS. Position of the American Dietetic Association: weight management. J Am Diet Assoc. Feb 2009;109(2):330-346.

162. Pallant J. SPSS Survival Manual. Vol 3rd edition. Berkshire, England: McGraw Hill Education; 2007. 